\title{
Nonpharmacologic Airway Clearance Techniques in Hospitalized Patients: A Systematic Review
}

\author{
Jeff Andrews MD, Nila A Sathe MA MLIS, Shanthi Krishnaswami MBBS MPH, \\ and Melissa L McPheeters PhD MPH
}

\author{
Introduction \\ Methods \\ Literature Search Strategy \\ Inclusion and Exclusion Criteria \\ Study Selection \\ Data Extraction and Synthesis \\ Quality (Risk of Bias) Assessment of Individual Studies \\ Results \\ Studies Evaluating CPT in Non-Postoperative Subjects \\ Studies in Postoperative Subjects \\ Discussion \\ Sputum Weight or Volume \\ Oxygenation and Gas Exchange \\ Pulmonary Function Tests \\ Need for and Progression to or Duration of Mechanical Ventilation \\ Signs and Symptoms \\ Exercise Tolerance \\ Pulmonary Complications \\ Stay \\ Exacerbations/Hospital Readmissions \\ Quality of Life \\ Harms of Airway Clearance Techniques \\ Methodologic Considerations and Limitations \\ Future Research \\ Summary
}

\begin{abstract}
Nonpharmacologic airway clearance techniques are used to reduce the sequelae of obstructive secretions. We systematically reviewed comparative studies of nonpharmacologic interventions that health professionals can employ to achieve mucus clearance in hospitalized or postoperative patients without cystic fibrosis, over the age of 12 months. We searched MEDLINE and other databases from 1990 to 2012 to identify relevant literature. Two reviewers independently assessed each study against predetermined inclusion/exclusion criteria. Two reviewers also independently extracted data regarding subject and intervention characteristics and outcomes, and assigned overall quality ratings. The 32 studies meeting the review criteria included 24 randomized controlled trials, 7 crossover randomized controlled trials, and one prospective cohort study. Studies were typically small and together included a total of 2,453 subjects (mean 76/study). Studies generally examined chest physical therapy/physiotherapy modalities in postoperative or critically ill subjects or those with COPD. Interventions, comparators, and populations varied considerably across studies, hampering our ability to draw firm conclusions. Interventions, including conventional chest physical
\end{abstract}


therapy/physiotherapy, intrapulmonary percussive ventilation, and positive expiratory pressure, typically provided small benefits in pulmonary function, gas exchange, oxygenation, and need for/duration of ventilation, among other outcomes, but differences between groups were generally small and not significant. Harms of the techniques were not consistently reported, though airway clearance techniques were generally considered safe in studies that did comment on adverse effects. Further research with clearly characterized populations and interventions is needed to understand the potential benefits and harms of these techniques. Key words: airway clearance techniques; chest physical therapy; breathing exercises; airway obstruction/therapy; physical therapy modalities. [Respir Care 2013;58(12):2160-2186. () 2013 Daedalus Enterprises]

\section{Introduction}

Airway clearance techniques are intended to reduce the sequelae of obstructive secretions, which can include airflow obstruction, wheeze, respiratory infection, dyspnea, fatigue, and reduced quality of life. ${ }^{1}$ Clearance techniques include modalities such as active cycle of breathing technique (ACBT), positive expiratory pressure (PEP) techniques such as the Flutter device, and intrapulmonary percussive ventilation (IPV). Conventional chest physical therapy or physiotherapy (CPT) approaches are frequently used as well, and include postural drainage, percussion, and vibration. Techniques may be categorized or grouped in multiple ways, and are often used in concert. Airway clearance approaches may be used in individuals with impaired cough or muscle weakness, ${ }^{2}$ impaired mucociliary clearance, ${ }^{3-6}$ structural impairments such as bronchiectasis or asthma, ${ }^{7-9}$ and air-flow limitation, as seen in COPD..$^{7,10-12}$

The goal of the current project was to systematically review comparative studies of nonpharmacologic interventions that respiratory therapists and other health professionals can employ to achieve mucus clearance in hospitalized or postoperative subjects over the age of 12 months. The American Association for Respiratory Care (AARC)

The authors are affiliated with the Vanderbilt Evidence-Based Practice Center, Institute for Medicine and Public Health, Vanderbilt University Medical Center, Nashville, Tennessee. Drs Andrews and McPheeters are also affiliated with the Department of Obstetrics and Gynecology, Vanderbilt University Medical Center, Nashville, Tennessee.

This review was supported by the American Association for Respiratory Care. The authors have disclosed no conflicts of interest.

Supplementary material related to this paper is available at http://www. rcjournal.com

Correspondence: Melissa McPheeters PhD MPH, Vanderbilt EvidenceBased Practice Center, Institute for Medicine and Public Health, Vanderbilt University Medical Center, Suite 600, 2525 West End Avenue, Nashville TN 37203-1738. E-mail: Melissa.mcpheeters@vanderbilt.edu.

DOI: $10.4187 /$ respcare.02704 commissioned the review, and AARC committee members participated in the review process. As a collaborative effort, the AARC team and the Vanderbilt Evidence-Based Practice Center developed the key questions and inclusion and exclusion criteria, and engaged in identification and review of abstracts. The AARC members involved in the work were paired with Vanderbilt Evidence-Based Practice Center staff in order to maintain rigor and protect against bias.

\section{Methods}

\section{Literature Search Strategy}

Detailed methods for this review and our search strategies can be found in the supplementary materials at http:// www.rcjournal.com. Our primary literature search employed the MEDLINE (via the PubMed interface) and Cumulative Index of Nursing and Allied Health Literature (CINAHL) databases. Our search strategies used a combination of subject heading terms appropriate for each database and key words relevant to airway clearance (eg, sputum clearance, CPT). We limited searches to literature published in English since 1990 to ensure that interventions used currently would be represented. Our searches were conducted in August 2012. We imported all citations into an electronic database and into the DistillerSR program for screening. We also manually searched the reference lists of included studies and of recent narrative and systematic reviews and meta-analyses addressing airway clearance in adults to locate citations of potential relevance.

\section{Inclusion and Exclusion Criteria}

Studies needed to include subjects over 1 year of age without cystic fibrosis, who were receiving nonpharmacologic airway clearance therapies and who were either hospitalized (but not postoperative) or postoperative, had neuromuscular disease or respiratory muscle weakness, or who had impaired cough. We note that we excluded studies of subjects with cystic fibrosis, as the Cystic Fibrosis Foun- 


\section{Nonpharmacologic Airway Clearance Techniques in Hospitalized Patients}

Table 1. Inclusion and Exclusion Criteria

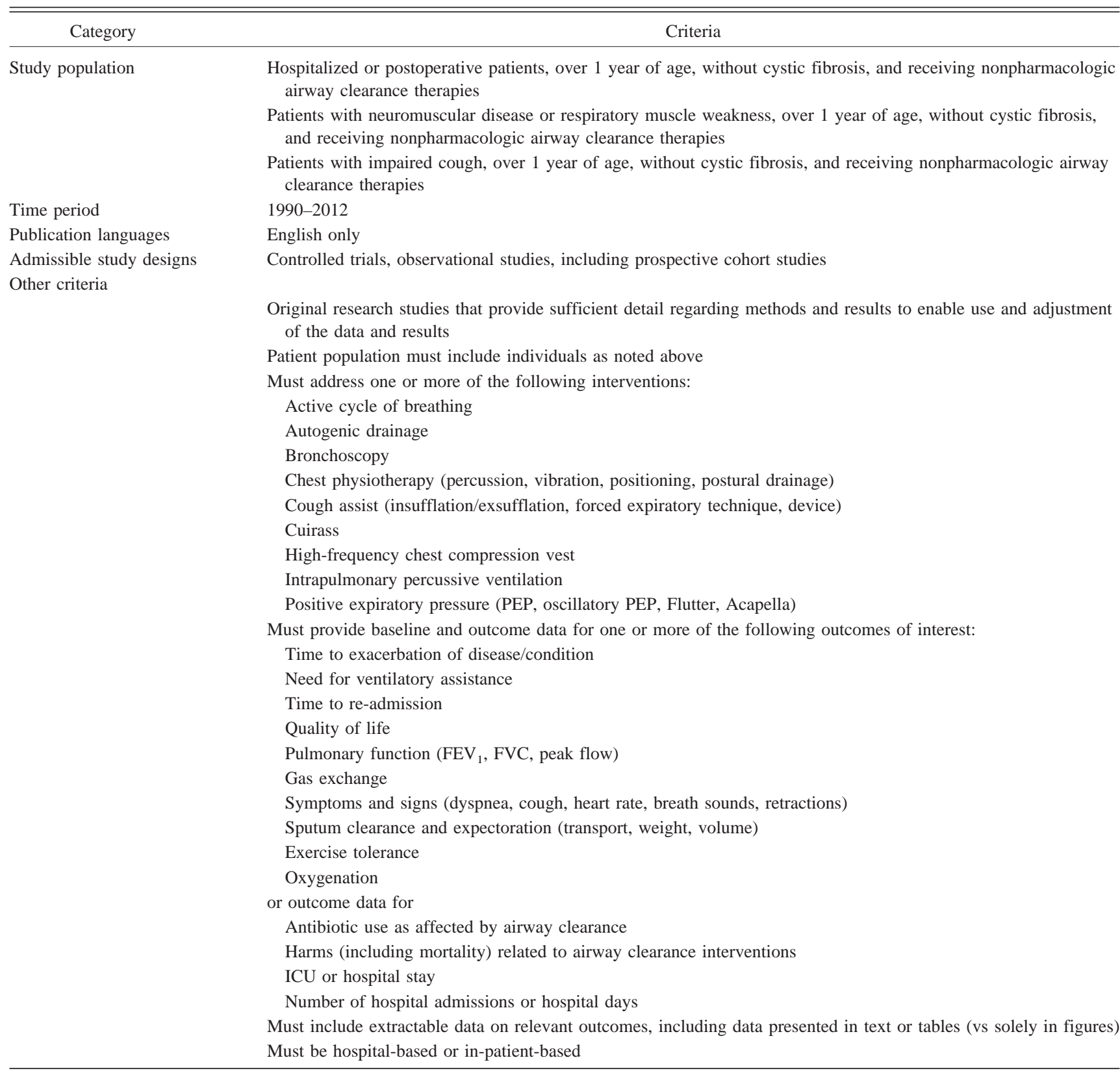

dation recently published guidelines specifically related to airway clearance. ${ }^{13}$ Studies had to report on interventions explicitly used for airway clearance and include a treatment group and an appropriate comparison group (Table 1). Comparators included other nonpharmacologic airway clearance approaches, no airway clearance intervention, or placebo. We also required that studies address one of the outcomes related to the effects of the intervention on mucus clearance outlined in Table 1. We included studies with any length of follow-up and in the hospital setting (ie, not home- or out-patient-clinic-based).

\section{Study Selection}

Once we identified potential articles, we examined the abstracts to determine whether studies met our criteria. Two reviewers separately evaluated each abstract for inclusion or exclusion, using an abstract review form (see the supplementary materials at http://www.rcjournal.com). If one reviewer concluded that the article could be eligible for the review based on the abstract, we retained it for full text assessment. Two reviewers independently assessed the full text of each included study, using a standardized 
Table 2. Quality Rating Algorithm

\begin{tabular}{lccc}
\hline \hline $\begin{array}{r}\text { Low Risk of } \\
\text { Bias Criteria }\end{array}$ & $\begin{array}{c}\text { High Risk of } \\
\text { Bias Criteria }\end{array}$ & $\begin{array}{c}\text { Unclear Risk } \\
\text { of Bias Criteria }\end{array}$ & Quality Level \\
\hline 7 & 0 & 0 & Good \\
6 & 0,1 & 0,1 & Good or fair \\
5 & 0,1 & 1,2 & Good or fair \\
5 & 2 & 0 & Fair or poor \\
4 & $0-2$ & $0-3$ & Fair or poor \\
$0-3$ & $0-7$ & $0-7$ & Poor \\
$0-7$ & $3-7$ & $0-7$ & Poor \\
$0-7$ & $0-7$ & $4-7$ & Poor \\
\hline
\end{tabular}

form (see the supplementary materials at http://www. rcjournal.com) that included questions stemming from our inclusion/exclusion criteria. Disagreements between reviewers were resolved by a third-party adjudicator. The group of abstract and full text reviewers included expert clinicians and health services researchers, and we required that studies be excluded by at least one clinician and one methodologist. AARC members involved in screening were paired with Vanderbilt Evidence-Based Practice Center staff in order to maintain rigor and protect against bias.

\section{Data Extraction and Synthesis}

We extracted data on study design, population characteristics (including age, underlying conditions, and need for mechanical ventilation), intervention characteristics (including type and duration of intervention and concomitant therapies), and key outcomes data into evidence tables (see the supplementary materials at http://www.rcjournal.com). In addition to outcomes related to airway clearance intervention effectiveness, we extracted all data available on harms of airway clearance. Harms encompass the full range of specific negative effects, including the narrower definition of adverse events. We determined that the differences among populations, interventions, controls, and outcome measures rendered meta-analysis inappropriate. Thus, our analysis was qualitative.

\section{Quality (Risk of Bias) Assessment of Individual Studies}

We assessed quality using separate tools, as appropriate by study design. Tools included the Cochrane Risk of Bias tool for randomized controlled trials (RCTs) and the Newcastle-Ottawa scale for cohort studies. We rated the quality for key outcomes for which data were provided. If a study noted, for example, that a given outcome was not significantly different between groups but did not provide the relevant data, we did not rate quality for that outcome. Two reviewers independently assessed the quality of each

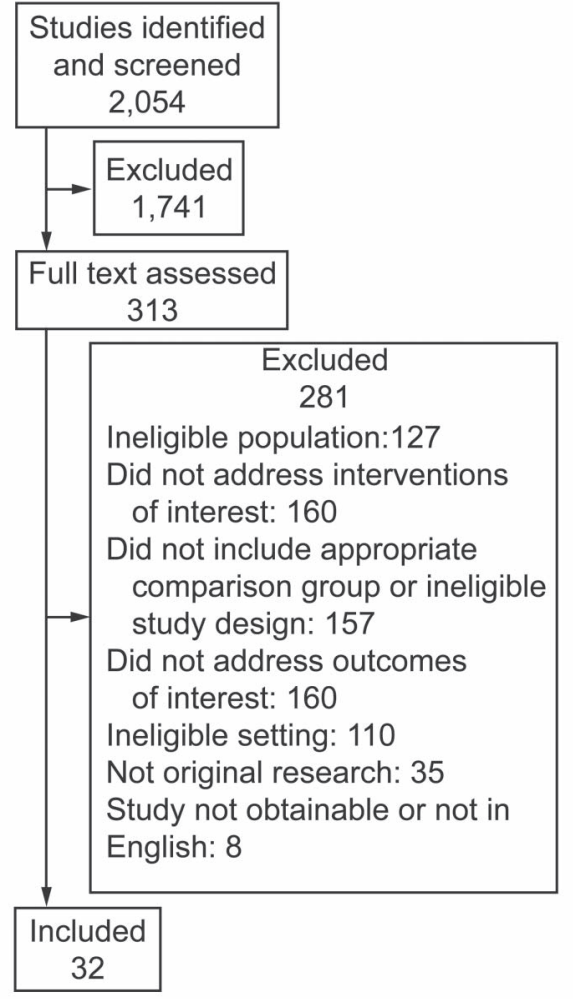

Figure. Flow chart of study selection.

study, with final decisions made via discussion to reach consensus or by third-party adjudication by a senior methodologist, as needed. We used the parameters outlined in Table 2 to translate quality ratings into final levels (good, fair, poor). We defined "good" studies as not having any of the criteria that create a high risk of bias. For studies with "unclear" ratings, we considered the likelihood that a factor would bias a given outcome and the importance of the limitation and down-graded the final level as appropriate. Quality ratings for each outcome in the studies reviewed can be found in the supplementary materials at http://www.rcjournal.com.

\section{Results}

We reviewed 2,054 abstracts and 313 full-text papers, and 32 papers (representing 32 separate studies) met the inclusion criteria (Figure). The excluded studies can be found in the supplementary materials at http://www. rcjournal.com. The 32 studies that met the review criteria included 24 RCTs, 7 crossover RCTs, and one prospective cohort study (Table 3 ). The studies were mostly small, and together included a total of 2,453 subjects (mean 76 subjects/study). Studies typically examined CPT modalities in postoperative or critically ill subjects or those with COPD. Subjects were typically assessed immediately following 
Table 3. Overview of Included Studies

\begin{tabular}{|c|c|c|c|c|}
\hline & RCT & $\begin{array}{l}\text { Crossover } \\
\text { RCT }\end{array}$ & $\begin{array}{l}\text { Prospective } \\
\text { Cohort }\end{array}$ & $\begin{array}{c}\text { All } \\
\text { Studies }\end{array}$ \\
\hline Number of studies & 24 & 7 & 1 & 32 \\
\hline \multicolumn{5}{|l|}{ Population } \\
\hline Adult & 18 & 7 & 1 & 26 \\
\hline Pediatric & 4 & 0 & 0 & 4 \\
\hline Mixed & 2 & 0 & 0 & 2 \\
\hline \multicolumn{5}{|l|}{ Underlying condition* } \\
\hline Asthma & 5 & 0 & 0 & 5 \\
\hline Bronchiectasis & 1 & 3 & 0 & 4 \\
\hline COPD & 8 & 2 & 1 & 11 \\
\hline $\begin{array}{l}\text { Pneumonia or other } \\
\text { pulmonary infection }\end{array}$ & 1 & 3 & 0 & 4 \\
\hline $\begin{array}{l}\text { Post-surgical/critical } \\
\text { illness/trauma }\end{array}$ & 13 & 3 & 1 & 17 \\
\hline \multicolumn{5}{|l|}{ Intervention category* } \\
\hline $\begin{array}{l}\text { Active cycle of breathing } \\
\text { technique }\end{array}$ & 0 & 1 & 0 & 1 \\
\hline Chest physical therapy & 19 & 4 & 1 & 24 \\
\hline $\begin{array}{l}\text { High-frequency chest wall } \\
\text { compression }\end{array}$ & 1 & 0 & 0 & 1 \\
\hline $\begin{array}{l}\text { Intrapulmonary percussive } \\
\text { ventilation }\end{array}$ & 3 & 1 & 0 & 4 \\
\hline Positive expiratory pressure & 6 & 4 & 0 & 10 \\
\hline \multicolumn{5}{|l|}{ Country } \\
\hline Asia & 2 & 3 & 0 & 5 \\
\hline Australia & 4 & 1 & 1 & 6 \\
\hline Europe & 9 & 2 & 0 & 11 \\
\hline South America & 2 & 1 & 0 & 3 \\
\hline United States or Canada & 5 & 0 & 0 & 5 \\
\hline Africa & 2 & 0 & 0 & 2 \\
\hline
\end{tabular}

* Numbers do not tally because studies may appear in more than one category. $\mathrm{RCT}=$ randomized controlled trial

short-term interventions or upon hospital or ICU discharge. Five studies followed subjects for one to 6 months postdischarge. ${ }^{14-18}$

The following sections summarize the results of studies that met our criteria, and are categorized by intervention and comparison in those studies, including primarily hospitalized, non-postoperative subjects (Table 4) and those focused on postoperative subjects (Table 5). Several studies of ICU populations included both postoperative subjects and subjects hospitalized for medical therapies. We have grouped these papers with studies of hospitalized subjects because their primary focus is not on the postoperative period.

\section{Studies Evaluating CPT in Non-Postoperative Subjects}

CPT Compared to Usual Care or Added to Another Treatment. Kodric and colleagues compared the "expiration with the glottis open in lateral posture" CPT tech- nique (expiration group, $n=30$ ) with standard medical treatment $(n=29)$ in subjects hospitalized with COPD exacerbation. ${ }^{16}$ Subjects in the expiration group also received standard medical therapy and were continued on medical therapy alone after 7 days of the expiration treatment (two 30-40 min sessions/d). Investigators analyzed subject respiratory data after 7 days of treatment, quality of life (St George's Respiratory Questionnaire [SGRQ]) 1 month post-discharge, and number of exacerbations and hospital admissions at 6 months post-discharge. The primary outcome of sputum volume was not significantly different between the groups after 7 days of treatment (mean $6.8 \pm 7.6 \mathrm{~mL} / \mathrm{d}$ in the expiration group, $8.2 \pm 9.4$ in the medical treatment only group), though the volume changes within each group differed significantly from baseline to follow-up ( $P \leq .001$ ). Dyspnea (Borg scale) was significantly reduced in the expiration group at 7 days $(3.0 \pm 1.8$ vs $4.3 \pm 1.5, P=.004)$. Stay was similar between groups (mean $9.5 \pm 3.2 \mathrm{~d}$ in the expiration group vs $10.0 \pm 2.4 \mathrm{~d}$ in the medical treatment only group). At 1 month post-discharge, quality of life scores were not significantly different between the groups. Similarly, at 6 months post-discharge, COPD exacerbations and hospitalizations did not differ significantly, though only roughly $37 \%$ of subjects in each group were available at the 6-month follow-up. We rated the quality of all the outcome assessed (pulmonary function, oxygenation, dyspnea, quality of life, sputum volume, stay, exacerbations) as poor.

In an RCT including mechanically ventilated ICU subjects, Templeton and Palazzo compared CPT (thoracic and pulmonary expansion; respiratory muscle exercise; and secretion removal via manual hyperinflation with vibration, positioning, and suctioning) with standard ICU care. ${ }^{21}$ The frequency and intensity of CPT could be varied at the therapist's discretion, and therapists were not blinded to subjects' group allocations. Control group subjects received suctioning, mobilization, and decubitus care, though all subjects could receive rescue CPT as needed (45 CPT and 37 control group subjects required rescue $\mathrm{CPT}$ at any time while ventilated). The mean age of the 87 subjects in the CPT group was 57.7 years (median Acute Physiology and Chronic Health Evaluation [APACHE] II score 49), while the corresponding values for the control group were 58.2 years and median APACHE II score of 41 . The groups were not significantly different at baseline. Reasons for ICU admission in both groups varied and included respiratory insufficiency $(n=21)$, intracerebral hemorrhage $(n=35)$, and gastrointestinal causes including bleeding and perforation $(n=18)$. The median number of days for half of subjects to become ventilator free was significantly lower in the control group than in the CPT group (11 d, range $3-76 \mathrm{~d}$, vs $15 \mathrm{~d}$, range $3-82 \mathrm{~d}, P=.045)$. Fourteen percent $(n=12)$ of the control subjects and $12.6 \%(n=11)$ of the CPT subjects required re-ventilation after becoming 


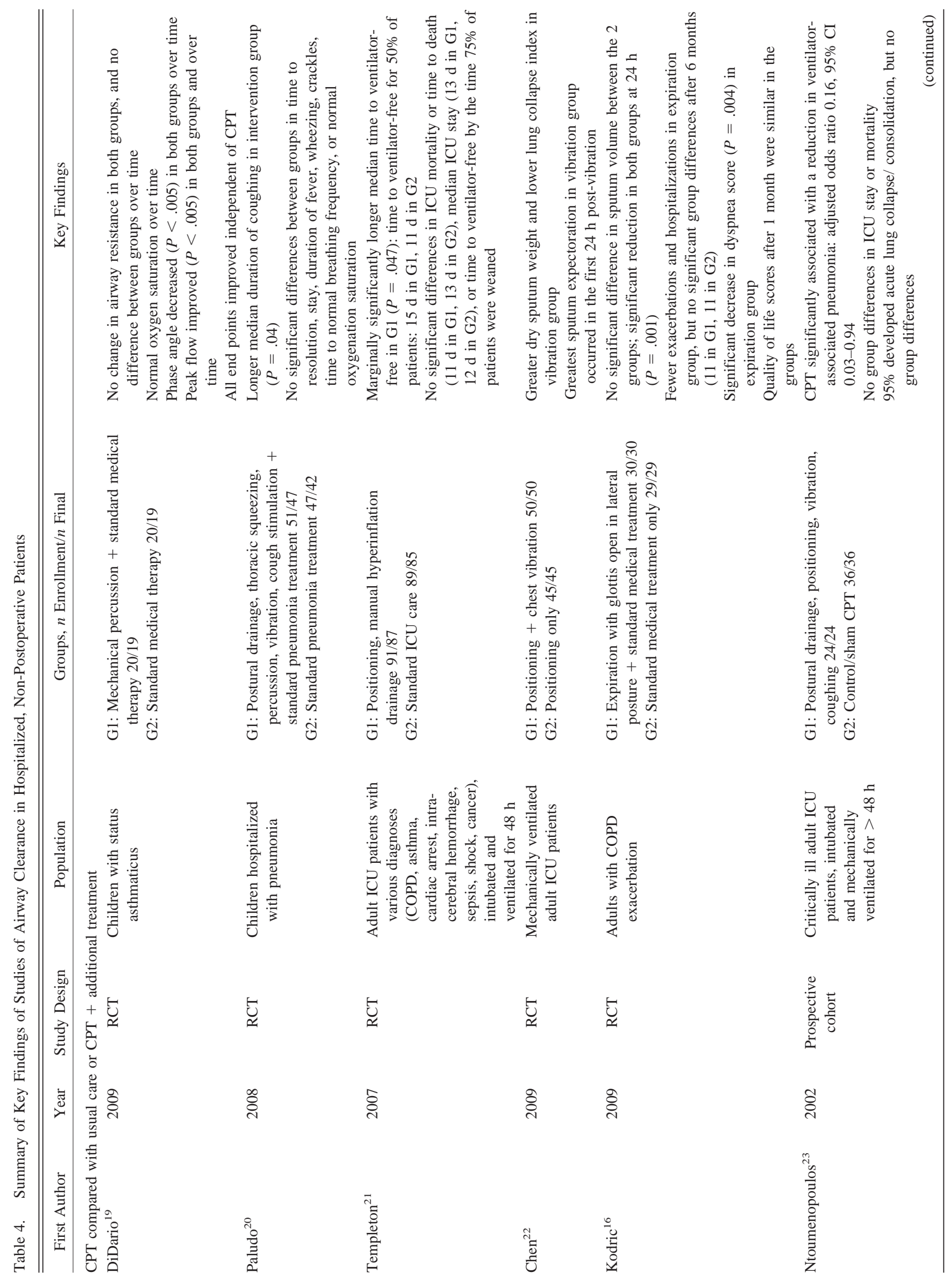




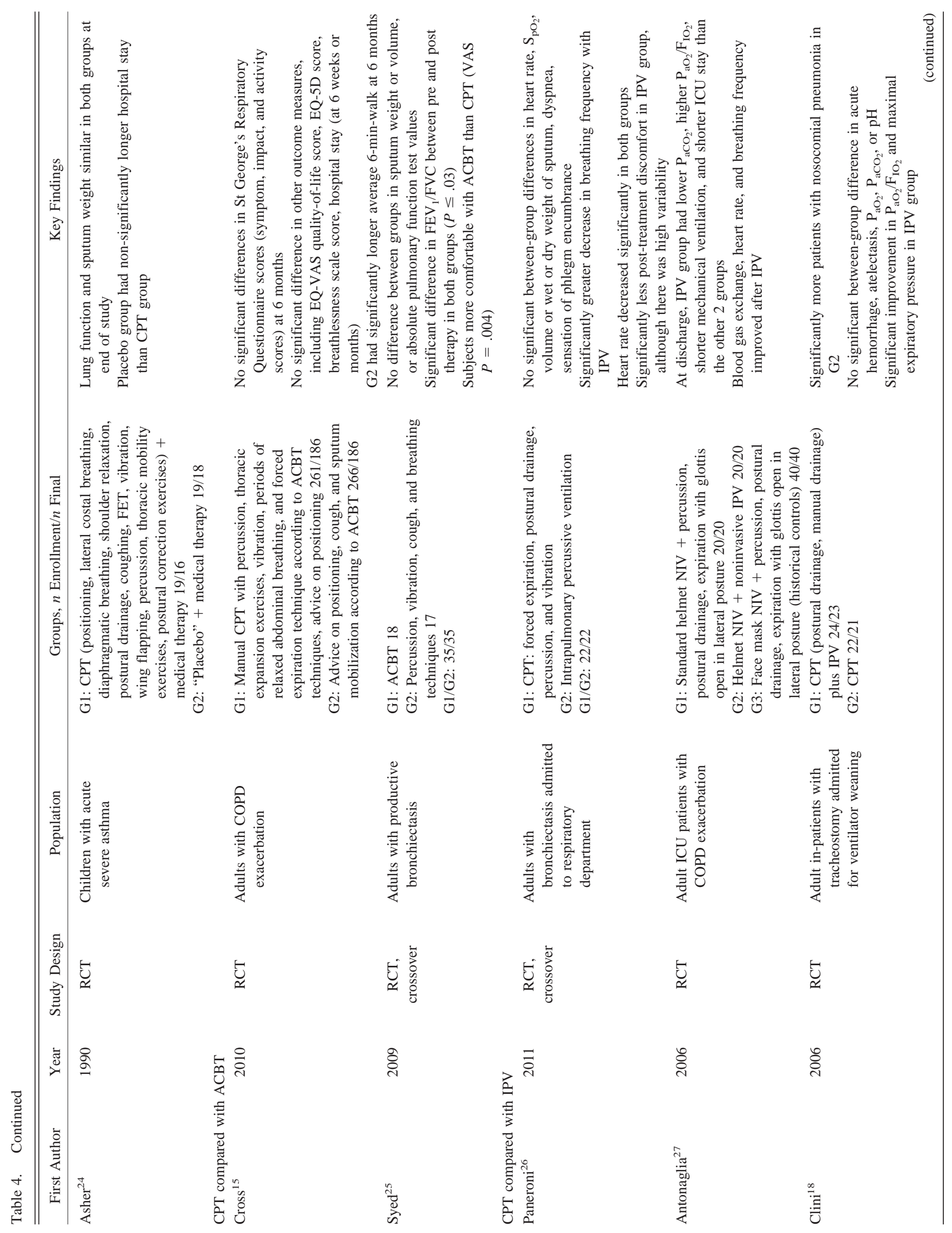




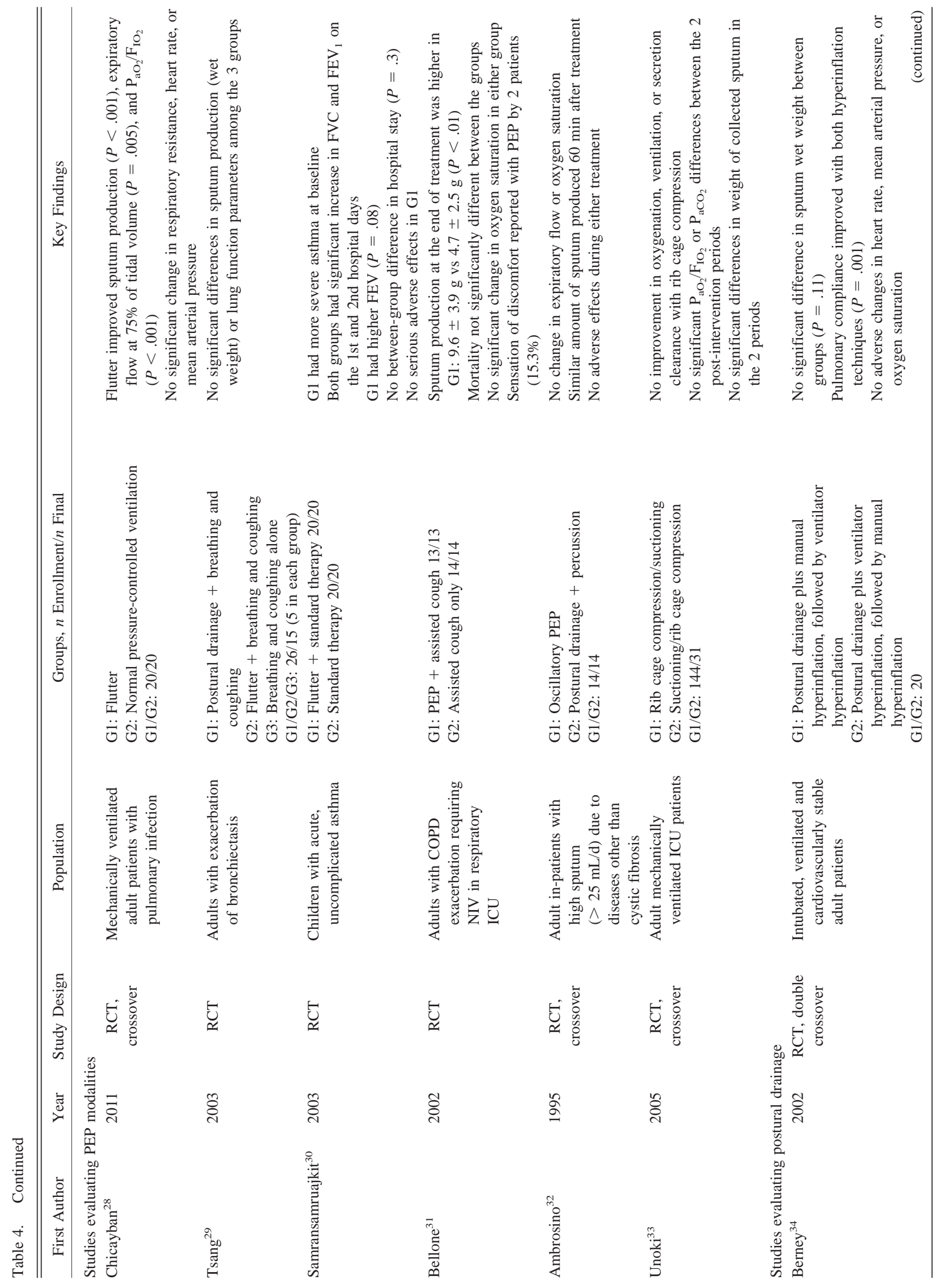




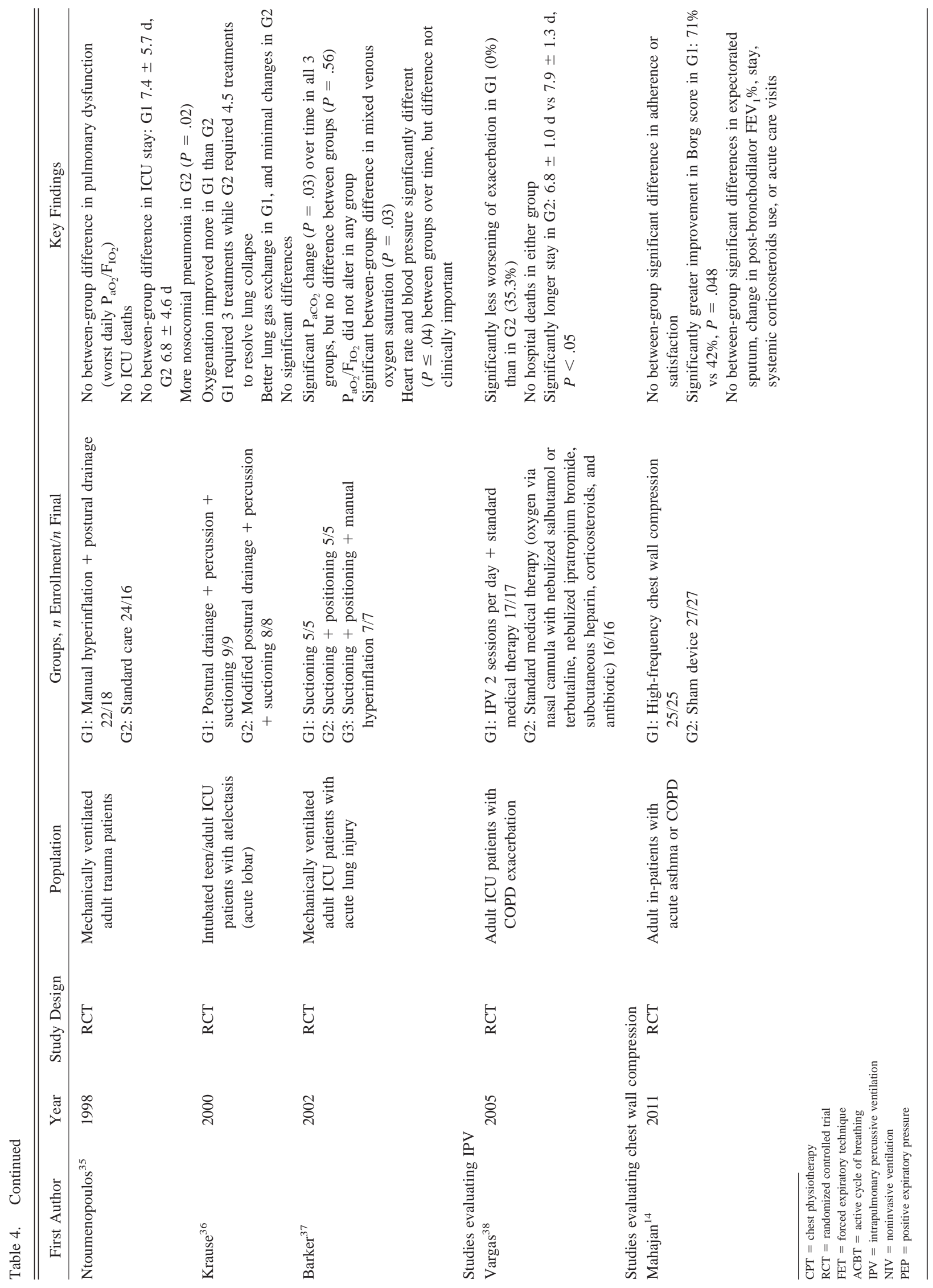




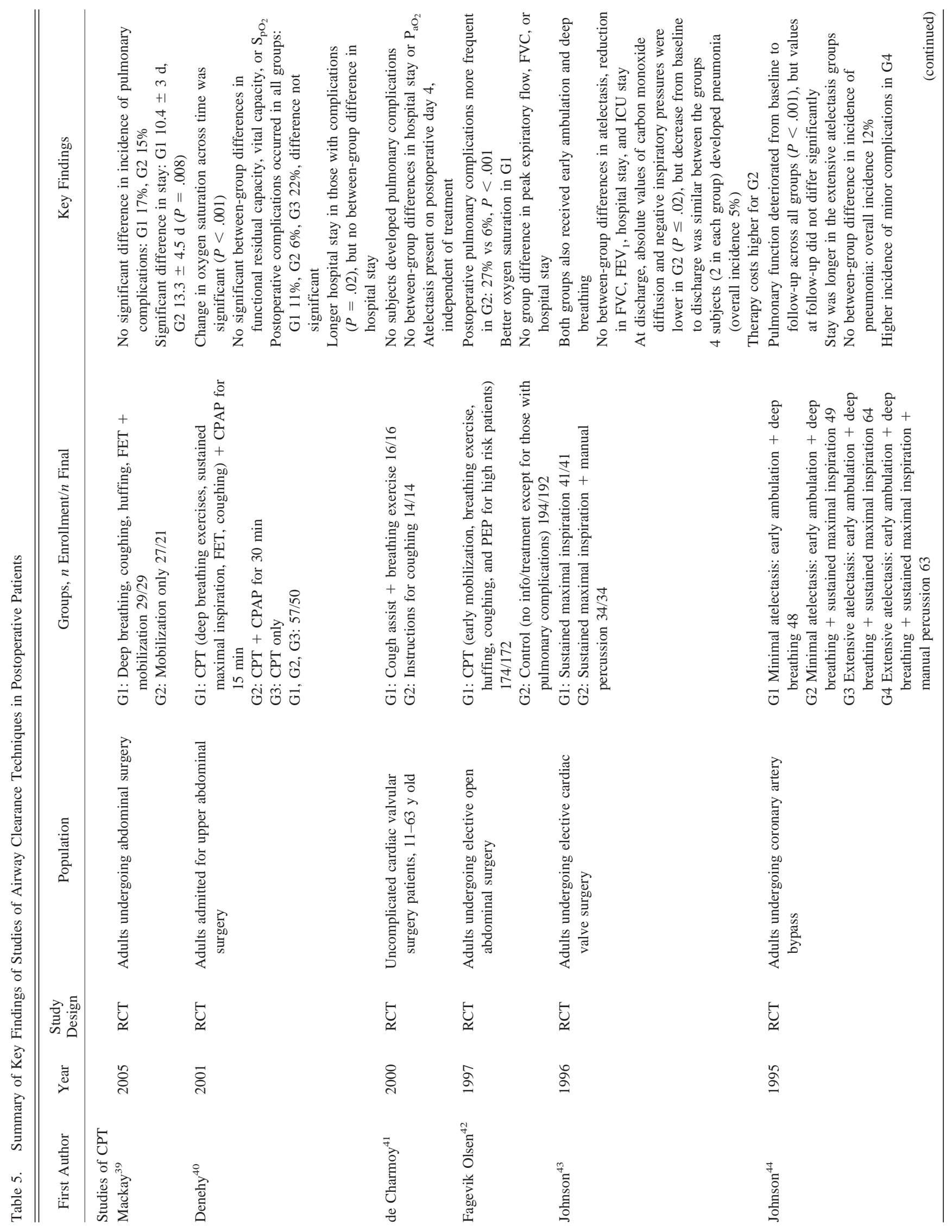




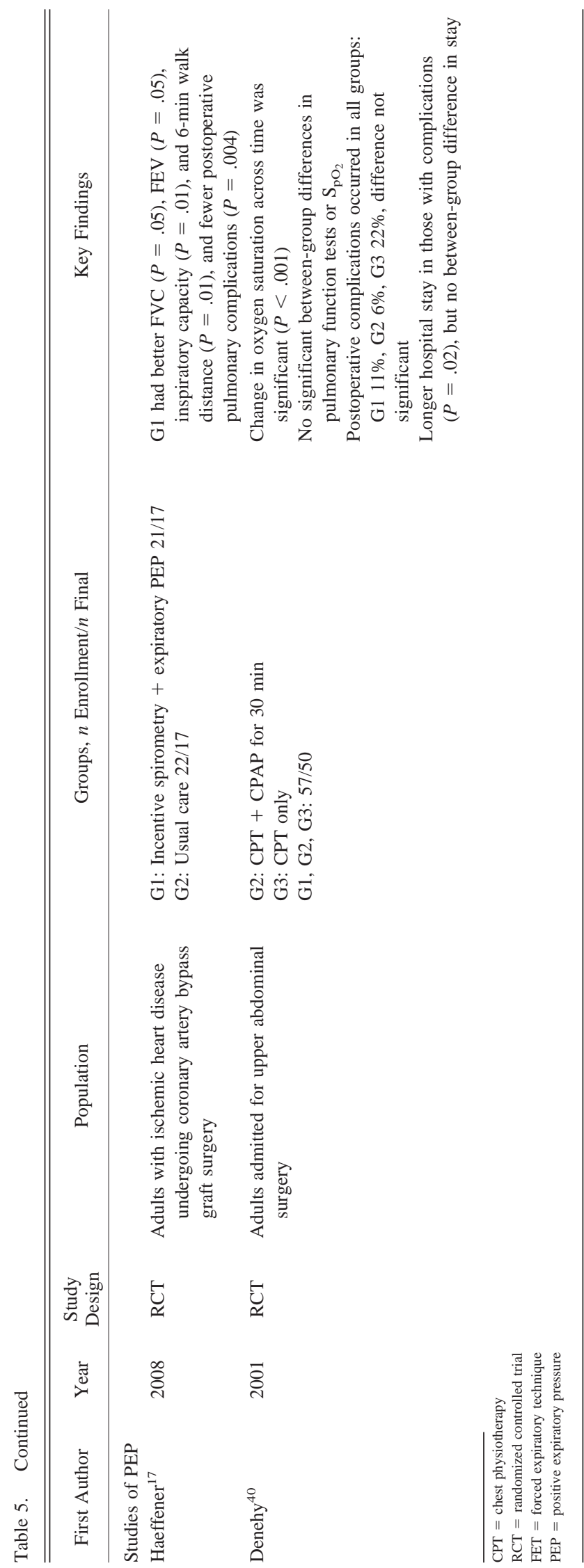

ventilator-free. The median ICU stay also differed significantly between the groups ( $13 \mathrm{~d}$ in CPT group, $12 \mathrm{~d}$ in control group). We rated the quality of the outcomes of stay and need for and duration of ventilation as fair.

In a cohort study including mechanically ventilated ICU patients, Ntoumenopoulos et al evaluated CPT compared with standard care for the prevention of ventilator-associated pneumonia (VAP). ${ }^{23} \mathrm{CPT}(n=24$ subjects, mean APACHE II score $20.7 \pm 6.9$ ) included postural drainage or positioning for at least $20 \mathrm{~min}$, expiratory chest wall vibration (4 sets of 6 cycles, with coughing added for subjects weaned from ventilator), and suctioning ( $\geq 3$ times). The control group ( $n=36$, mean APACHE II score $18.8 \pm 5.4$ ) received sham CPT, consisting of cardiopulmonary assessment and occasional musculoskeletal physical therapy plus re-positioning and suctioning as needed. Both groups received standard medical and nursing care, which included hemodynamic support, infection care, enteral nutrition, antibiotic therapy, and bronchoscopy, as needed. The subjects' underlying conditions included COPD (6 in the CPT group, 11 in the control group), cardiomyopathy ( 1 in the CPT group, 3 in the control group), and cardiac arrest ( 3 in the CPT group, 5 in the control group). Groups were similar at baseline in terms of risk factors for VAP; however, among the surgical subjects the American Society of Anesthesiologists score was higher in the control arm $(P=.04)$. Significantly more subjects in the control arm developed VAP (14 vs $2, P=.01$ ). The duration of ventilation, ICU stay, and number with lung collapse or consolidation were nonsignificantly lower in the CPT group: median ventilation days 4.4 vs 5.2, median ICU days 5.6 vs 5.8 , number with lung collapse/consolidation 23 vs 34 . We rated this cohort study as good quality.

In an RCT that included mechanically ventilated ICU subjects, 20-85 years old, Chen and colleagues compared mechanical chest vibration (via vibration pad used in supine position, $60 \mathrm{~min} / \mathrm{session}, 6$ times/d over $72 \mathrm{~h}$ ) plus routine positioning in 50 subjects, to routine positioning alone in 45 subjects. ${ }^{22}$ Underlying conditions in both groups included sepsis (38\%), respiratory failure (37\%), and surgery $(31 \%)$. Sixteen percent of subjects had COPD, and $27 \%$ had had cerebrovascular accident. The subjects were not significantly different at baseline: mean APACHE II score $25.4 \pm 6.6$ in the positioning-only group versus $23.1 \pm 7.2$ in the vibration group. Mean dry sputum weight at baseline was $5.74 \pm 6.23 \mathrm{mg} / 24 \mathrm{~h}$ in the vibration group and $5.42 \pm 3.98 \mathrm{mg} / 24 \mathrm{~h}$ in the positioning-only group. After 72 hours, sputum weight was $4.04 \pm 3.43 \mathrm{mg} / 24 \mathrm{~h}$ in the vibration group versus $3.56 \pm 3.10 \mathrm{mg} / 24 \mathrm{~h}$ in the positioning-only group. However, when the investigators used generalized estimating equations to address the longitudinal nature of the data and account for correlation, the differences in sputum weight were significant between 


\section{Nonpharmacologic Airway Clearance Techniques in Hospitalized Patients}

groups, with sputum greater in the intervention group $(P<.001)$. The lung collapse index of the vibration group was significantly improved, compared with the positioning group at 72 hours (mean $0.96 \pm 0.73$ vs $1.60 \pm 0.91$, $P<.001)$. We rated the quality of the outcome of sputum volume findings as poor.

Paludo et al conducted an RCT with children ( $29 \mathrm{~d}$ to 12 y old) hospitalized with acute pneumonia, and compared twice-daily CPT and standard pneumonia therapy $(n=51)$ to standard treatment alone $(n=47) .{ }^{20} \mathrm{CPT}$ sessions were $30 \mathrm{~min}$ in duration and included postural drainage, thoracic squeezing, chest percussion, vibration, cough stimulation, and suctioning as needed. Standard medical therapy included antibiotics, fluids, and oxygen therapy as needed. The subjects were similar at baseline. There were no significant differences at follow-up in stay, time to normal breathing frequency, time to normal oxygen saturation, time to normal auscultation, or duration of wheezing, crackles, or chest in-drawing. The CPT group had a longer median duration of coughing $(5.0 \mathrm{~d}$ vs $4.0 \mathrm{~d}$, $P=.04$ ) and longer duration of rhonchi (median $2.0 \mathrm{~d}$ vs $0.5 \mathrm{~d}, P=.03$ ) than the medical treatment only group. We rated the quality of the outcomes of stay and time to normal breathing frequency and oxygenation as fair.

In an RCT assessing CPT as an adjunct to medical therapy in children with asthma, Asher and colleagues randomized subjects hospitalized with acute asthma to placebo $(n=19)$ or CPT with modalities selected at the discretion of the therapist $(n=19) .{ }^{24}$ CPT included relaxation techniques (positioning, lateral costal or diaphragmatic breathing, shoulder relaxation), secretion clearance techniques (postural drainage, coughing, forced expiratory technique, vibration, wing flapping), thoracic mobility exercises, and postural correction exercises.

Each subject received a total of 4 treatment or placebo sessions. The placebo was a 20-min visit from a hospital volunteer who provided emotional support. CPT sessions were 20-30 min long and included the modalities described above, selected by the therapist for each child. Relaxation techniques were most frequently used at the first and fourth treatment sessions (used in $95 \%$ and $84 \%$ of sessions, respectively). Secretion clearance techniques were used in $79 \%$ of the first treatment sessions and $74 \%$ of the fourth. The medical therapy included nebulized salbutamol, theophylline, and steroids, and the use of medical therapies were similar at baseline. The subjects' mean age was approximately 10 years, the mean onset of asthma was at roughly age 2 , and the mean asthma severity score was approximately 2.3 on a scale of 1 (mild) to 3 (severe). Three children ( 1 in the placebo group, 2 in the CPT group) completed the study twice, due to readmissions. Lung function did not differ significantly between the groups at baseline or follow-up. Sputum production was measured in $26 \%$ of the CPT sessions, and the weight range was $0.7-10.8 \mathrm{~g}$. Stay was non-significantly longer in the placebo group. We rated the quality of the outcomes of stay and pulmonary function tests as fair.

An RCT that included children with asthma (ages 4-18 y) admitted with status asthmaticus randomized the subjects to either CPT plus standard medical therapy $(n=20)$ or standard medical therapy alone $(n=20) .{ }^{19}$ CPT included 6 sessions (one each hour over $24 \mathrm{~h}$ ) of percussion with a pneumatic chest percussor for $20 \mathrm{~min}$, after nebulized albuterol administration. Medical therapy included inhaled $\beta_{2}$ agonists and systemic steroids. The investigators measured airway resistance at baseline and follow-up, with impulse oscillometry, and the initial measurement occurred a mean $12 \pm 6$ hours after admission; thus, the subjects had some degree of improvement before the baseline measurement. Oxygen saturation did not differ from baseline to follow-up in either group, whereas peak flow improved in both groups from baseline to follow-up $(P<.005)$. The differences in peak flow between the groups were not significant. Airway resistance did not change significantly in either group from baseline to follow-up. The differences in airway resistance between the groups as a function of time or steroid use were not significant. We rated the quality of the outcome of oxygenation as poor.

CPT Compared With ACBT. The Management of Exacerbations of COPD (MATREX) RCT allocated subjects hospitalized with COPD to either CPT plus ACBT or ACBT alone. ${ }^{15} \mathrm{CPT}$ included manual positioning, percussion during thoracic expansion, and vibration upon expiration, and ACBT techniques included forced expiration. The number and duration of CPT treatments was up to the discretion of the therapist, although the CPT treatments themselves were standardized. Subjects randomized to ACBT alone received advice on positioning and ACBT to mobilize sputum. Subjects in both groups also received standard medical therapy. Subjects were followed for 6 months after randomization, and primary outcomes were scores on the SGRQ and European Quality of Life-5 Dimensions (EQ-5D) and visual analog scales (EQ-VAS). The mean age of the 258 subjects randomized to the CPT group was $69.08 \pm 9.85$ years, the mean baseline SGRQ total score was $68.94 \pm 14.66$, and the mean baseline EQ-VAS was $44.95 \pm 21.03$. The ACBT-only arm included 264 subjects (mean age $69.58 \pm 9.51 \mathrm{y}$, mean baseline SGRQ total score $69.13 \pm 14.76$, mean EQ-VAS $46.64 \pm 21.42$ ). Differences between the groups at baseline were not significant.

The CPT subjects received a median of 2 CPT sessions (median duration $11 \mathrm{~min}$, median 2 positions/session). At 6 months the between-group differences in COPD-specific quality of life were not significant in the adjusted (for baseline value and hospital site) or unadjusted intentionto-treat analyses (mean SGRQ symptoms score effect size 


\section{Nonpharmacologic Airway Clearance Techniques in Hospitalized Patients}

in the adjusted analysis $0.04,95 \% \mathrm{CI}-0.15$ to 0.23 ; mean SGRQ activity score effect size in the adjusted analysis $-0.02,95 \%$ CI -0.20 to 0.16 ; mean SGRQ impact score effect size in the adjusted analysis $0.02,95 \% \mathrm{CI}$ -0.15 to 0.18 ). All of the $95 \%$ confidence intervals were within the study's predefined limits for equivalence. Similarly, quality of life ratings on the EQ-VAS (effect size $2.65,95 \% \mathrm{CI}-2.37$ to 7.65 ) and EQ-5D (effect size -0.01 , $95 \% \mathrm{CI}-0.07$ to 0.06 ) were not significantly different in the adjusted or the unadjusted intention-to-treat analyses. Mean stay was not significantly different between the groups (CPT $16.02 \pm 16.57 \mathrm{~d}$, ACBT $16.85 \pm 18.11 \mathrm{~d}$ ). The mean number of hospital admissions during the 6-month follow-up period was 3.47 for the CPT group and 3.89 for the ACBT group (significance not reported). At 6 months the control group performed significantly better on the 6-min walk test (mean difference 83.23, 95\% CI 13.09-153.37). The CPT subjects reported 15 adverse, events, including increased shortness of breath $(n=5)$, pain $(n=5)$, arrhythmia $(n=3)$, bronchospasm $(n=1)$, and thoracic hematoma $(n=1)$. The investigators did not consider these harms that compromised patient safety. We rated the quality of the outcomes of stay, exacerbations/ readmissions, and harms of airway clearance techniques as fair, and the quality of the outcomes of dyspnea, exercise tolerance, and quality of life as poor. ${ }^{15}$

Syed et al included 35 adults with bronchiectasis in a crossover RCT that compared short-term CPT to ACBT. ${ }^{25}$ They used a convenience sample of subjects undergoing medical therapy for bronchiectasis, allocating them to either CPT (percussion and vibration in various postural drainage positions, cough, and deep breathing techniques in 20-30 min sessions every $3 \mathrm{~h}$ ) or ACBT (huffing, deep breathing, and relaxed breathing cycles for a maximum of $30 \mathrm{~min}$ in various postural drainage positions). Intervention sequences were separated by 12 hours over 2 days. The mean age of the 35 subjects was $45.8 \pm 11.2$ years, 25 were smokers, and 17 had a history of tuberculosis. The wet weight or volume of expectorated sputum did not differ significantly between treatments at follow-up (mean weight difference $0.96 \pm 17.7 \mathrm{mg}$, mean volume difference $-1.68 \pm 20.50 \mathrm{~mL}, P<.05)$. FVC, $\mathrm{FEV}_{1}$, and $\mathrm{FEV}_{1} / \mathrm{FVC}$ also did not differ between treatment sequences. The subjects rated ACBT as more comfortable on a $10 \mathrm{~cm}$ visual analog scale (median 8 vs 5 for CPT, $P=.004$ ). We rated the quality of the outcomes of pulmonary function and sputum volume as poor.

CPT Compared With IPV. Paneroni et al evaluated IPV and CPT in a crossover RCT that included 22 subjects with bronchiectasis. ${ }^{26}$ The mean age of the subjects was $64.4 \pm 8.9$ years, and the mean percent-of-predicted $\mathrm{FEV}_{1}$ was $53 \pm 30 \%$. The IPV arm included 3 active cycles alternating high and low pressure for $30 \mathrm{~min}$. CPT in- cluded forced expiration, postural drainage, percussion, and vibration in 3 positions, for a total of $30 \mathrm{~min}$. At follow-up there was no significant difference in mean sputum volume or wet or dry sputum weight between the groups. $\mathrm{S}_{\mathrm{pO}_{2}}$ also did not differ between the groups. Heart rate fell significantly from baseline to follow-up in both groups, but did not differ between the groups. Breathing frequency decreased significantly in the IPV group from baseline, but not for CPT, and the difference between groups at the final follow-up was also significant $(P=.047)$. Dyspnea improved significantly from baseline $(P=.004)$ in the IPV group also, but the between-group differences were not significant. Harms were reported by both groups, and included dry throat, nausea, and/or fatigue (27\% of both groups). Post-treatment discomfort was lower with IPV than with CPT $(P=.03)$. We rated the quality of the outcomes as: oxygenation good, sputum volume fair, and heart rate, breathing frequency, dyspnea, and harms poor.

Antonaglia et al randomized subjects with COPD undergoing helmet noninvasive ventilation (NIV) to either CPT $(n=20)$ or IPV $(n=20) .{ }^{27}$ CPT included $25-30 \mathrm{~min}$ of chest percussion, mobilization, postural drainage, and expiration with the glottis open in lateral posture. IPV consisted of 25-30 min sessions of mouthpiece IPV delivering high-flow mini-bursts at 225 cycles/min. The subjects also received medical treatments as required. The groups were similar at baseline: mean age $69 \pm 7$ years in the CPT group versus $72 \pm 7$ years in the IPV group; median APACHE II score 22 in both groups. Twentyseven subjects in both groups were hypersecretive $(\geq 30 \mathrm{~mL}$ secretions/d). The investigators assessed differences with an overall analysis of variance, and included data from a historical control group in the analysis. Differences between the groups at discharge were not significant for median breathing frequency, heart rate, or mean arterial pressure. $\mathrm{P}_{\mathrm{aCO}}$ and $\mathrm{P}_{\mathrm{aO}} / \mathrm{F}_{\mathrm{IO}_{2}}$ differed significantly between the groups at discharge: mean $\mathrm{P}_{\mathrm{aCO}_{2}}: 64 \pm 5.2 \mathrm{~mm} \mathrm{Hg}$ in the CPT group, $58 \pm 5.4$ in the IPV group, $67 \pm 4$, $P<.01$; mean $\mathrm{P}_{\mathrm{aO}_{2}} / \mathrm{F}_{\mathrm{IO}_{2}} 218 \pm 34.2 \mathrm{~mm} \mathrm{Hg}$ in the CPT group, $274 \pm 14.8 \mathrm{~mm} \mathrm{Hg}$ in the IPV group, $237 \pm 20 \mathrm{~mm} \mathrm{Hg}$ in the historical control group, $P<.01$. The IPV group had higher $\mathrm{P}_{\mathrm{aO}_{2}} / \mathrm{F}_{\mathrm{IO}_{2}}$ and lower $\mathrm{P}_{\mathrm{aCO}}$. In both groups 7 subjects required intubation and mechanical ventilation (vs NIV), but the IPV group required a lower median number of hours of ventilatory assistance $(61 \mathrm{~h}$ vs $89 \mathrm{~h}, P$ value not reported). Median ICU stay was also lower for the IPV group $(7 \mathrm{~d}$ vs $9 \mathrm{~d}$ for CPT, $P$ value not reported). Four subjects in the CPT group and 2 in the IPV developed sepsis or pneumonia ( $P$ value not reported). We rated the quality of the outcomes of gas exchange, stay, mean arterial pressure, and need for and duration of ventilation as fair. We rated the quality of the outcomes of heart rate and breathing frequency as poor. 
Clini and colleagues evaluated the effectiveness of IPV in ICU subjects with tracheostomy recently weaned from mechanical ventilation. ${ }^{18}$ The 46 subjects included 6 postcardiac surgery subjects, 8 neuromuscular disease/impairment subjects, and 22 COPD or chronic respiratory insufficiency subjects. The groups were similar at baseline, and all the subjects were hypersecretive ( $\geq 40 \mathrm{~mL}$ secretions/ d). The investigators allocated the subjects to either 15 days of IPV (2 sessions/d) plus CPT $(n=24)$, or CPT alone $(n=22)$. CPT in both groups comprised 2 one-hour sessions per day of postural and manual drainage, followed by nebulized saline and repeat of the drainage maneuvers with suctioning. In the IPV group $\mathrm{P}_{\mathrm{aO}_{2}}$ increased significantly from baseline $(69 \pm 8 \mathrm{~mm} \mathrm{Hg}$ to $76 \pm 9 \mathrm{~mm} \mathrm{Hg}$, $P<.05)$, as did $\mathrm{P}_{\mathrm{aO}_{2}} / \mathrm{F}_{\mathrm{IO}_{2}}(238 \pm 51 \mathrm{~mm} \mathrm{Hg}$ to $289 \pm 52 \mathrm{~mm} \mathrm{Hg}, P=.005)$. Maximal expiratory pressure also significantly increased from baseline to day 15 in the IPV group $\left(34 \mathrm{~cm} \mathrm{H}_{2} \mathrm{O}\right.$ [12\%] to $47 \mathrm{~cm} \mathrm{H}_{2} \mathrm{O}$ [1\%], $P=.005$ ) and as compared with the CPT-only group $(P<.05)$. The mean differences in $\mathrm{P}_{\mathrm{aO}_{2}} / \mathrm{F}_{\mathrm{IO}_{2}}$ and maximal expiratory pressure between the groups were, respectively, $21.65 \mathrm{~mm} \mathrm{Hg}$ $(95 \% \mathrm{CI}-11.75$ to $55.05 \mathrm{~mm} \mathrm{Hg}, P=.04)$ and $9.26 \mathrm{~mm} \mathrm{Hg}$ (95\% CI 1.98-16.54 mm Hg, $P=.01$ ). At day 15, 2 subjects in the CPT arm and one in the IPV arm had any pulmonary complications. At the 1-month follow-up, no IPV subjects had any complications, whereas 2 in the CPT group had pneumonia $(P<.05$ for comparison of pneumonia between groups at all time points). We rated the quality of pulmonary function and gas exchange as poor.

PEP Modalities With and Without CPT. In an RCT that included 30 subjects with bronchiectasis (mean age $50.7 \pm 6.4 \mathrm{y}$, mean $\mathrm{FEV}_{1} 21 \%$ of predicted), the subjects received Acapella or inspiratory muscle training, in a crossover study design. ${ }^{45}$ Acapella treatment included 10 breaths at near maximum capacity followed by breath-hold, active exhalation, and coughing or huffing after every 5 breaths. Use of the inspiratory muscle trainer similarly included 10 breaths at maximal inspiratory effort, followed by breathhold, active exhalation, and coughing/huffing after every 5 breaths. Treatment occurred at the same time over 3 consecutive days, with medications administered $\geq 1$ hour prior to treatment. The medications included inhaled $\beta$-agonists $(n=17)$, inhaled corticosteroids $(n=2)$, oral antibiotics $(n=15)$, and oral corticosteroids $(n=2)$. Expectorated sputum was significantly greater in the Acapella group: mean $\pm \mathrm{SD} 7.16 \pm 1.12 \mathrm{~mL}$ vs $6.46 \pm 1.08 \mathrm{~mL}$, $P=.02$, mean difference $0.70 \mathrm{~mL}, 95 \%$ CI $0.13-1.27$ ). The subjects rated Acapella as more useful in clearing secretions, but ratings of convenience, comfort, and overall performance did not differ significantly between the modalities. We rated the quality of the outcome of sputum volume as poor.
In an RCT that included ICU subjects with COPD exacerbation, Bellone et al evaluated 3 daily, 30-40 min sessions of PEP plus assisted cough compared with assisted cough alone. ${ }^{31}$ All the subjects received NIV until they met the weaning criteria or the criteria for intubation, and all received medical therapy (nebulized salbutamol, nebulized ipratropium bromide, intravenous methylprednisolone, antibiotics). The subjects were similar at baseline: PEP group: $n=13$, mean age $65 \pm 7.8 \mathrm{y}$, mean APACHE II score $16.6 \pm 1.1$; assisted-cough-only group: $n=14$, mean age $64 \pm 7.7 \mathrm{y}$, mean APACHE II score $17 \pm 1.2$ ). Sputum production was higher in the PEP group at the end of treatment $(9.6 \pm 3.9 \mathrm{~g}$ vs $4.7 \pm 2.5 \mathrm{~g}$, $P<.01$ ), and continued to increase in the $60 \mathrm{~min}$ following treatment in the PEP subjects, but not in the assistedcough-only group. The PEP group also required fewer days to wean from NIV $(4.9 \pm 0.8 \mathrm{~d}$ vs $7.0 \pm 0.7 \mathrm{~d}$, $P<.01)$. No subjects in the PEP group, and one in the assisted-cough-only group progressed to intubation. PEPrelated harms included discomfort from the PEP mask, reported by 2 subjects (15.3\%), neither of whom stopped treatment during the study. We rated the quality of the outcomes of duration of ventilation as fair, and that for sputum volume as poor.

In a crossover RCT including mechanically ventilated ICU subjects, Unoki and colleagues compared rib cage compression (one 5-min session) plus endotracheal suctioning to suctioning alone. ${ }^{33}$ Intervention sequences were separated by 3 hours. The subjects (mean age $56.7 \pm 17.6 \mathrm{y}$, mean Simplified Acute Physiology score $59.4 \pm 10.7$ ) were hospitalized for various causes, including intracerebral hemorrhage (19\%), cardiac arrest (19\%), pneumonia (12\%), and cerebral infarction (12\%). Forty-two percent of the subjects had radiographic evidence of atelectasis. Sputum weight, $\mathrm{P}_{\mathrm{aO}_{2}} / \mathrm{F}_{\mathrm{IO}_{2}}$, and $\mathrm{P}_{\mathrm{aCO}}$ did not differ significantly between the intervention periods. The quality of the outcome of gas exchange was poor.

Studies Assessing the Flutter Valve. Ambrosino and colleagues compared the effects of the Flutter device to postural drainage plus percussion in 14 subjects hospitalized with COPD, bronchiectasis, bronchitis, or silicosis, on sputum production and patient discomfort in a crossover RCT..$^{32}$ Each subject underwent 2 sessions of postural drainage and manual chest percussion or breathing through the Flutter device. Each session could be conducted for up to $30 \mathrm{~min}$, at the discretion of the subject, and the subject could cough and perform deep breathing as desired during each treatment. Treatments were separated by a 24-hour wash-out period, so the study extended over 8 days. The subjects continued their standard medical therapies throughout the study. At baseline the subjects produced a mean of $51 \pm 27 \mathrm{~mL}$ of sputum/d and had a mean $\mathrm{FEV}_{1}$ of $49 \pm 26 \%$ of predicted. Sputum production increased 


\section{Nonpharmacologic Airway Clearance Techniques in Hospitalized Patients}

significantly, by roughly $10 \mathrm{~mL}$, during both treatment sequences $(P<.001$, compared with baseline for each treatment) and was non-significantly increased over baseline at 60 min post-treatment. The subjects' self-rated feelings of "chest unpleasantness due to sputum" improved significantly from baseline to $60 \mathrm{~min}$ post-treatment with both treatment sequences $(P<.001)$. $\mathrm{FEV}_{1}$, FVC, peak flow, and oxygen saturation remained stable and did not differ significantly across the time points. We rated the quality of the outcomes of pulmonary function, oxygenation, and sputum volume as poor.

In a single-blind RCT that included 15 subjects hospitalized with bronchiectasis exacerbation, Tsang and Jones compared 3 airway clearance modalities (each delivered once a day for 15 min until discharge): postural drainage plus breathing and coughing exercises, Flutter and breathing/coughing, and breathing/coughing alone. ${ }^{29}$ Each group included 5 subjects with the mean age/group ranging from 66.8 to 64.2 years. Mean percent-of-predicted $\mathrm{FEV}_{1}$ at baseline ranged from $36.10 \%$ to $48.47 \%$. The groups were similar at baseline, though there were more smokers in the breathing/coughing-only group (4/5 vs $1 / 5$ in the posturaldrainage-plus-breathing/coughing group, and $3 / 5$ in the Flutter group, $P$ value not reported). Mean stay was similar among the groups: $7.2 \pm 3.3 \mathrm{~d}$ in the postural-drainage-plus-breathing/coughing group, $6.2 \pm 3.83 \mathrm{~d}$ in the Flutter group, and $5.2 \pm 0.84 \mathrm{~d}$ in the breathing/coughingonly group. Similarly, the wet weight of sputum expectorated did not differ significantly among the groups at any time point. FVC, $\mathrm{FEV}_{1}$, and peak expiratory flow also did not differ significantly from baseline to follow-up within the groups or between the groups. The subject-rated scores of effectiveness were higher in the Flutter group than in the breathing/coughing-only group at all time points $(P<.05)$. The effectiveness scores did not differ significantly between the Flutter and postural-drainage-plusbreathing/coughing group. We rated the quality of the outcome of stay as fair. We rated the quality of the outcomes of pulmonary function and sputum weight as poor.

In a crossover RCT that included 20 mechanically ventilated subjects with pulmonary infection and hypersecretion in an adult ICU, Chicayban et al compared Flutter to normal pressure controlled ventilation. ${ }^{28}$ The subjects were mechanically ventilated for a mean 21.6 days, had a mean APACHE II score of 21.7, and $75 \%$ had VAP. The subjects received normal ventilation or two 15-min sessions of Flutter, separated by a 6-hour wash-out period. At follow-up immediately after the intervention, secretion production was greater in the Flutter group: $5.1 \pm 0.5 \mathrm{~mL}$ vs $3.3 \pm 0.3 \mathrm{~mL}(P<.001)$. In the Flutter group static compliance increased significantly from baseline $(P<.001)$, as did peak flow $(P=.008)$ and expiratory flow at $75 \%$ of tidal volume $(P=.005)$. Respiratory mechanics did not change significantly in the control sub- jects. In the Flutter group mean airway pressure increased significantly from baseline $(P<.05)$, and compared with the control group $(P<.05)$. The end-tidal partial pressure of $\mathrm{CO}_{2}$ increased significantly from baseline in the control group $(P<.05)$ and in the Flutter subjects as compared with the control group $(P<.05)$. Oxygen saturation also increased significantly in the Flutter group, compared with control $(P<.05)$. We rated as good the quality of the outcomes of oxygenation and arterial pressure. We rated as fair the quality of the outcomes of pulmonary function, gas exchange, heart rate, and sputum volume.

Samransamruajkit and colleagues randomized children (6-16 y old) hospitalized for acute asthma to either Flutter (15-20 min session) plus medical therapy, or medical therapy alone. ${ }^{30}$ Subjects in the medical therapy group also had instructions to cough. The baseline age and pulmonary characteristics were similar between the groups, except for initial asthma score (mean 5.9 in Flutter group vs 4.45 in the medical treatment group, $P<.01$ ) and oxygen requirement (mean 30 in the Flutter group vs 25 in the medical treatment group, $P<.05$ ). At day 3 of the study the between-group differences in oxygen saturation, $\mathrm{F}_{\mathrm{IO}_{2}}$, and asthma score were not significant; however, only 5 subjects in each group remained at that point. The mean posttreatment asthma score had decreased significantly in the Flutter group, compared with the medical-treatment group on day $2(1.3 \pm 0.3$ vs $2.5 \pm 0.3, P=.01)$. Stay was not significantly different between the groups, and no serious adverse events were reported in the Flutter group (harms not specified). We rated the quality of the outcomes of oxygenation and stay as fair. We rated the quality for pulmonary function as poor.

Studies Evaluating Postural Drainage. Berney and Denehy included 20 mechanically ventilated ICU subjects in a crossover RCT that compared postural drainage plus manual hyperinflation followed by ventilatory hyperinflation to postural drainage plus ventilator hyperinflation followed by manual hyperinflation. ${ }^{34}$ In both groups the foot of the bed was elevated and the subjects were placed in a side-lying position before undergoing 6 sets of 6 manual or ventilator hyperinflation breaths and suctioning. The subjects received both treatments, separated by 2 hours, on each of 2 days. The subjects (mean age 45.2 y, APACHE II score range $10-22)$ had spinal injury $(n=12,10$ with quadriplegia), multiple trauma $(n=4)$, respiratory failure $(n=1)$, and other indications. After the 2-day study the mean sputum production in the manual hyperinflation group was $6.53 \mathrm{~g} \mathrm{(95 \%} \mathrm{CI} \mathrm{5.86-7.20)} \mathrm{and} \mathrm{6.01} \mathrm{g}$ in the ventilator hyperinflation group (95\% CI 4.83-7.19 g); those weights did not differ significantly: mean difference $2.65 \mathrm{~g}, 95 \% \mathrm{CI}$ $1.79-3.54 \mathrm{~g})$. Both treatments significantly improved $(P<.001)$ static pulmonary compliance from baseline, with a mean percentage improvement of $9.7 \%$ with man- 


\section{Nonpharmacologic Airway Clearance Techniques in Hospitalized Patients}

ual hyperinflation (95\% CI 46.5-54.9) and $11.6 \%$ with ventilator hyperinflation (95\% CI 45.5-54.7). Mean arterial pressure, heart rate, and arterial oxygen saturation did not change adversely with either treatment. We rated the quality of the outcome of sputum weight as poor.

Ntoumenopoulos and colleagues assessed the effects of manual hyperinflation plus postural drainage, compared with usual care, on pulmonary complications in mechanically ventilated trauma subjects in an RCT. ${ }^{35}$ The subjects in the manual hyperinflation group $(n=22)$ received 6 hyperinflation breaths, repeated 4 times, in postural drainage positions, for $20 \mathrm{~min}$, plus suctioning as needed between sets and routine turning. The control subjects $(n=24)$ received routine nursing care (suctioning as needed and turning twice an hour). The groups were similar at baseline (treatment group: mean age $38.85 \pm 16.62 \mathrm{y}$, mean APACHE II score $12.3 \pm 3.8$; control group: mean age $41.20 \pm 20.15 \mathrm{y}$, mean APACHE II score $14.1 \pm 7.4$ ). Days on mechanical ventilation, ICU days, and level of pulmonary dysfunction (worst daily $\mathrm{P}_{\mathrm{aO}_{2}} / \mathrm{F}_{\mathrm{IO}_{2}}$ ) were similar between the groups at follow-up. Four subjects in the treatment group and 8 in the control were withdrawn from the study per protocol, because of suspected pneumonia; 3 subjects in the treatment and 4 in the control group were diagnosed with pneumonia. We rated the quality of the outcomes of pulmonary function, stay, and duration of ventilation as good.

An RCT by Krause et al included mechanically ventilated ICU subjects with atelectasis of the lower lobes, and compared standard postural drainage to modified postural drainage. ${ }^{36}$ Subjects were $13-85$ years old and had conditions that included bronchial obstruction $(n=2)$, rib fracture or surgery $(n=5)$, pleural effusion $(n=3)$, pneumonia $(n=3)$, Guillain-Barré syndrome $(n=1)$, and pneumothorax/hemothorax $(n=3)$. The subjects received 15 min of either standard postural drainage (one of 4 positions, depending on the location of lung collapse, each including elevation of the foot of the bed,) following inhalation of mucolytics $(n=9)$, or modified postural drainage (supine, side-lying, or 1/4 prone positioning, depending on location of lung collapse) following mucolytics $(n=8)$. Both groups received percussion for $5 \mathrm{~min}$, and suctioning following positioning. The study did not report whether or not the subjects were statistically similar at baseline. The standard drainage group required a mean of 3 treatments to resolve the collapse, compared with 4.5 in the modified-postural-drainage group ( $P$ value not reported). Arterial blood gas values $\left(\mathrm{P}_{\mathrm{aO}_{2}}\right.$, oxygen saturation, diffusion capacity, alveolar/arterial oxygen difference, respiratory index, and venous shunt value) improved more from baseline to final treatment in the standard-posturaldrainage group, though the differences were not significant. We rated the quality of the outcome of gas exchange as fair.
Barker and Adams conducted an RCT to assess the effects of a single session of commonly used CPT modalities on pulmonary function and oxygenation in mechanically ventilated subjects with acute lung injury. ${ }^{37}$ The subjects were randomly allocated to either supine positioning plus suctioning $(n=5$, mean age $73 \pm 2.6 \mathrm{y})$, lateral decubitus positioning plus suctioning $(n=5$, mean age $70 \pm 7.4 \mathrm{y}$ ), or lateral decubitus positioning plus 6 manual hyperinflation breaths plus suctioning $(n=7$, mean age $70 \pm 16.3 \mathrm{y})$. The subjects were hospitalized with sepsis $(n=7)$, aspiration pneumonia $(n=5)$, community-acquired pneumonia $(n=4)$, and pancreatitis $(n=1)$. The study does not indicate if the baseline differences among the groups were significant. Venous oxygenation saturation did not change significantly over time within or among the groups, though it was lower in the lateral-decubituspositioning-plus-suctioning group at all time points $(P=.03) . \mathrm{P}_{\mathrm{aCO}_{2}}$ and $\mathrm{P}_{\mathrm{aO}_{2}} / \mathrm{F}_{\mathrm{IO}_{2}}$ also did not differ within groups or among groups at the 60-min follow-up. Dynamic compliance and mean arterial pressure did not differ among the groups at follow-up. Heart rate varied significantly within and among groups over time $(P<.05)$. We rated the quality of the outcome of gas exchange as fair. We rated the quality of the outcomes of heart rate and mean arterial pressure as poor.

\section{Studies Evaluating Intrapulmonary Percussive Venti-} lation. Vargas et al conducted an RCT comparing standard medical and oxygen therapy to standard therapy plus IPV via face mask in ICU subjects with COPD. ${ }^{38}$ The 16 subjects in the IPV group had a mean age of 69.2 years and a mean $\mathrm{FEV}_{1}$ of $39 \%$ of predicted. Those values in the standard therapy group were 70.2 years and $38 \%$. The groups were not significantly different at baseline. IPV subjects received the same medical treatment as the control group (supplemental oxygen, nebulized salbutamol or terbutaline, nebulized ipratropium bromide, subcutaneous heparin, corticosteroids, oral methylprednisolone, antibiotic, correction of electrolyte abnormalities) plus 2 daily 30-min IPV sessions (mean duration of therapy $3 \pm 1 \mathrm{~d}$ ). No subject in either group received any additional airway clearance modalities. Six subjects in the standard treatment group had a worsening of exacerbation and required NIV, compared with 0 subjects in the IPV group $(P<.05)$. Stay was also significantly longer in the standard therapy group $(7.9 \pm 1.3 \mathrm{~d}$ vs $6.8 \pm 1 \mathrm{~d}, P<.05)$. Breathing frequency and $\mathrm{P}_{\mathrm{aCO}}$ decreased significantly from baseline to the end of the first IPV session in the IPV group, whereas $\mathrm{P}_{\mathrm{aO}_{2}}$ increased $(P<.05)$; these values were not reported for the standard therapy group. We rated the quality of the outcomes of pulmonary function, need for ventilation, oxygenation, and stay as fair. We rated the quality of the outcome of breathing frequency as poor. 
Studies Evaluating Chest Wall Compression. Mahajan and colleagues assessed hospitalized adults ( $\geq 18 \mathrm{y}$ old) with physician-diagnosed acute asthma and/or COPD in an RCT sponsored by the manufacturer of the pneumatic vest evaluated. ${ }^{14}$ The investigators randomly allocated 25 subjects (median age $46.5 \mathrm{y}$ ) to high-frequency chest wall compression (the Vest, Hill-Rom, St Paul, Minnesota) and 27 subjects (median age 50.4 y) to sham chest wall compression, which provided a sensation of vibration but without air flow oscillation. The subjects also received standardized medical treatment (albuterol, systemic or inhaled corticosteroids, supplemental oxygen, other medications as needed). Roughly $60 \%$ of subjects in each group had asthma, and 40\% had COPD. Baseline characteristics did not differ significantly between groups; subjects in both groups had a median of one hospitalization in the year preceding the current admission.

After 60 total minutes of treatment or sham treatment administered over 2 days, dyspnea was significantly improved in the treatment group, compared with the sham group (median change in Borg dyspnea score -1.5 vs 0 , $P=.048)$. The differences in spontaneously expectorated sputum, $\mathrm{FEV}_{1} \%$, and hospital stay were not significant. Four subjects in each group reported an acute care visit (hospitalization or emergency department visit) in the 30day follow-up period. Subject satisfaction and adherence to both the treatment and the sham treatment were high. We rated the quality of all the outcomes (pulmonary function, dyspnea, sputum, stay, and time to readmission) as good. ${ }^{14}$

\section{Studies in Postoperative Subjects}

Studies Evaluating CPT. Johnson and colleagues stratified subjects by degree of atelectasis in an RCT that compared CPT modalities of graduated intensity (combinations of early ambulation plus deep breathing, sustained maximal inspirations, and percussion) in post-coronaryartery-bypass subjects. ${ }^{44}$ The investigators randomly allocated subjects with minimal atelectasis on chest $\mathrm{x}$-ray to either early mobilization plus deep breathing (group 1, $n=48$ ) or early mobilization plus deep breathing plus sustained maximal inspirations (group 2, $n=49$ ). Subjects with marked atelectasis were allocated to either early mobilization plus deep breathing plus sustained maximal inspirations (group 3, $n=64$ ) or all of those modalities plus percussion (group 4, $n=63$ ). Mobilization included graduated increases in activity. Deep breathing instructions were for 5 deep breaths/hour daily, recorded by the subject in a log. Sustained maximal inspiration comprised stacked inhalations to total lung capacity, with a 5-second breathhold, for 5 repetitions, conducted once each waking hour, with position changes as tolerated. Percussion sessions (3/d) consisted of 1 or 2 cupped hand percussions/s to the chest wall during the total lung capacity phase of a sustained maximal inspiration.

The subjects were similar at baseline in all preoperative and pulmonary function parameters except, as per proto$\mathrm{col}$, degree of atelectasis. All the pulmonary function values (vital capacity, $\mathrm{FEV}_{1}$, functional residual capacity, maximum expiratory pressure, negative inspiratory pressure, carbon monoxide diffusion) deteriorated significantly in all groups from baseline to discharge $(P<.001)$, though the discharge values did not differ significantly among the groups. ICU stay was significantly greater $(P<.05)$ in group $3(2.3 \pm 0.8 \mathrm{~d})$ and group $4(2.3 \pm 0.6 \mathrm{~d})$ than in groups 1 or 2 (both groups stay $2.0 \pm 0.5 \mathrm{~d}$ ). Hospital stay was significantly longer $(P<.05)$ in group $3(9 \pm 2.7 \mathrm{~d})$ and group $4(10 \pm 8.5 \mathrm{~d})$ than in the other groups $(8 \pm 1.5 \mathrm{~d}$ or $1.6 \mathrm{~d}$ ). Eight subjects in group 1, 10 in group 2, 14 in group 3, and 13 in group 4 met the criteria for pneumonia, with an overall incidence of $12 \%$. No subjects developed respiratory failure, and none required repeat ICU admission because of respiratory complications. Percussion was associated with minor complications; however, only data for falling oxygen saturation (below 90\% in 7/295 treatments) and tachycardia (12/295 treatments) were reported. None of those episodes was associated with important blood pressure changes. We rated the quality of the outcomes of pulmonary function, stay, and pulmonary complications as poor. ${ }^{44}$

In a related study, Johnson et al randomized subjects undergoing cardiac valve surgery to the same regimen of either early mobilization and deep breathing exercises plus sustained maximal inspirations (group 1) or early mobilization, deep breathing exercises, sustained maximal inspirations, and 2 sessions of percussion/day (group 2)..$^{43}$ This study most likely involved some of the same subjects as Johnson's earlier study in bypass subjects, ${ }^{44}$ though the precise extent of overlap is unclear. The 41 subjects in group 1 and 34 in group 2 were similar in most characteristics at baseline; however, the subjects in group 2 were older, by approximately 5 years $(63 \pm 12$ years vs $68 \pm 10$ years, $P=.004$ ). Pulmonary function values decreased in both groups from baseline to discharge, with changes in $\mathrm{FVC}$, functional residual capacity, $\mathrm{FEV}_{1} \%$, and carbon monoxide diffusion reaching statistical significance in both groups $(P<.001)$. Carbon monoxide diffusion was significantly lower in group 2 than in group 1 at discharge $(15 \pm 5 \mathrm{~mL} / \mathrm{min} / \mathrm{mm} \mathrm{Hg}$ vs $10 \pm 2.4 \mathrm{~mL} / \mathrm{min} /$ $\mathrm{mm} \mathrm{Hg}, P<.05)$, as was negative inspiratory pressure $\left(39 \pm 19 \mathrm{~cm} \mathrm{H}_{2} \mathrm{O}\right.$ vs $\left.33 \pm 14 \mathrm{~cm} \mathrm{H}_{2} \mathrm{O}, P<.05\right)$. Atelectasis scores at discharge and ICU stay and hospital stay were similar between the groups. Two subjects in each group developed pneumonia, for an overall incidence of $5 \%$. No subject progressed to respiratory failure, and none required ICU readmission for respiratory complications. 


\section{Nonpharmacologic Airway Clearance Techniques in Hospitalized Patients}

We rated the quality of all the outcomes (pulmonary function, heart rate, stay, pulmonary complications) as poor.

In an RCT on CPT following cardiac valve surgery, de Charmoy and Eales allocated surgical subjects to receive either coughing and mobilization instructions $(n=$ $14)$ or CPT $(n=16)$, including positioning and breathing and coughing exercises, with sessions twice a day on postoperative days 1 and 2 and once a day on days 3 and $4.4^{41}$ The CPT subjects also received assisted walking at each treatment session. The subjects were similar at baseline, with an overall mean age of 29.72 years (range 11-63 y). $\mathrm{P}_{\mathrm{aO}}$ declined significantly in both groups from baseline, but the values at follow-up did not differ significantly between the groups. Stay did not differ between the groups. No subjects in either group developed pulmonary complications, including pneumonia. We rated the quality of the outcomes gas exchange and pulmonary complications as poor.

In an RCT on the effectiveness of deep breathing and sputum clearance techniques in reducing post-abdominalsurgery pulmonary complications, Mackay et al randomized 56 subjects to either early post-surgical mobilization $(n=21)$ or early mobilization plus deep breathing ("coached lateral basal expansion") exercises and airway clearance maneuvers (coughing huffing, forced expiratory technique).$^{39}$ The deep breathing group $(n=29)$ received therapy 3 times a day on postoperative day 1, twice a day on days 3 and 4, and then daily until the subject was mobile and had a clear chest assessment for 3 consecutive days. The subjects were also encouraged to practice the deep breathing techniques independently during each waking hour. Early mobilization included graduated assisted and independent walking, as tolerated, plus leg flexion exercises, performed independently. One early-mobilization-only subject (who was later withdrawn from the study) was mistakenly given deep breathing exercises; the investigators analyzed data for that subject by intention-to-treat and with the deep breathing group.

The mean age of the 50 study completers was 66 years, and the groups were similar at baseline: 14 treatment subjects and 11 early-mobilization-only subjects had a history of chronic airway limitation or pulmonary disease. Surgery types in both groups included colectomy/hemicolectomy $(n=26)$, bowel resection $(n=4)$, gastrectomy/ esophagectomy $(n=6)$, and abdominoperineal resection $(n=3)$. The incidence of postoperative pulmonary complications (defined as $\geq 3$ respiratory signs, including auscultation changes, fever, chest $\mathrm{x}$-ray changes, and increase or change in sputum), did not differ between the groups (17\% in the treatment group vs $14 \%$ in the mobilizationonly group). The absolute risk reduction was $-3.0 \%$ ( $95 \%$ CI -0.22 to $0.19 \%$ ). Stay was longer in the mobilization-only group (mean $13 \pm 4.5 \mathrm{~d}$ vs $10.4 \pm 3.0 \mathrm{~d}$, $P=.008$, difference in means $2.9,95 \%$ CI $0.77-5.03 \mathrm{~d}$ ).
Mean ICU stay was similar between the groups, as was the need for mechanical ventilation: 2 subjects in each group required mechanical ventilation, for $2 \mathrm{~d}$ in the control group, and $0.75 \mathrm{~d}$ in the treatment group. We rated the quality of the outcomes stay, pulmonary complications, and need for and duration of ventilation as good. ${ }^{39}$

In another RCT in post-abdominal surgery subjects, Fagevik Olsén et al compared preoperative and postoperative CPT to no CPT on the incidence of pulmonary complications. ${ }^{42}$ The CPT group $(n=174)$ underwent preoperative CPT (10-15 min of breathing exercises, huffing and coughing, education about positioning and mobilization) on the day before surgery, and postoperative CPT (15-20 min sessions conducted hourly by the subject, and including deep breathing plus huffing and coughing) thereafter for an unspecified duration. The investigators also preoperatively classified the subjects in each group as low or high risk, based on age $\geq 50$ years plus one of: smoker or recent ex-smoker, body mass index $\geq 30 \mathrm{~kg} / \mathrm{m}^{2}$, pulmonary disease with need for daily medication, or history of other condition causing reduced ventilatory function. High risk subjects in the CPT group also received PEP mask for respiratory resistance training during breathing exercises. The control subjects received no preoperative training and no postoperative CPT unless a pulmonary complication was diagnosed, at which point they received CPT plus PEP mask. The groups did not differ significantly at baseline. Postoperative pulmonary complications (defined as oxygen saturation $<92 \%$ or 2 of: fever, negative auscultation, or radiologic evidence of pneumonia or atelectasis) were diagnosed in $10(6 \%)$ CPT subjects, 6 of whom were considered high risk, and 52 (27\%, 20 considered high risk) in the control arm $(P<.001)$. Among the obese subjects, 3 CPT subjects and 27 control subjects developed complications $(P<.001)$. One CPT subject and 13 control subjects were diagnosed with pneumonia, for an overall incidence rate of $4 \%$. Vital capacity and peak expiratory flow declined significantly in all subjects from baseline to follow-up, but differences between groups were not significant. Hospital stay was also not significantly different (mean $8.8 \pm 4.5 \mathrm{~d}$ in the CPT group, $9.0 \pm 5.1$ in the control group). The study did not indicate the duration or modalities of CPT provided to the 52 control subjects with pulmonary complications, who presumably received postoperative CPT per protocol. We rated the quality of the outcomes of pulmonary function and complications, heart rate, and stay as poor.

Studies Evaluating PEP Modalities With and Without CPT. Denehy and colleagues compared twice-daily standard CPT (coughing and deep breathing, including sustained maximal inspirations and forced expiratory technique for a minimum of $10 \mathrm{~min}$ ) to CPT plus either 15 or 30 min sessions of CPAP, 4 times per 24 hours, in an RCT 


\section{Nonpharmacologic Airway Clearance Techniques in Hospitalized Patients}

that included post-abdominal surgery subjects. ${ }^{40}$ The investigators encouraged the subjects in each group to walk early and to perform deep breathing exercises independently each hour, though adherence to the protocol was not tracked. Among the 50 study completers, 18 were randomized to CPT only (mean age $73.3 \pm 5.8 \mathrm{y}$, mean preoperative $\mathrm{FEV}_{1} 2.3 \pm 0.6 \mathrm{~L}$ ), 17 to $15 \mathrm{~min}$ of CPAP (mean age $72.5 \pm 6.5 \mathrm{y}$, mean $\mathrm{FEV}_{1} 2.3 \pm 0.8 \mathrm{~L}$ ), and 15 to 30 min of CPAP (mean age $70.5 \pm 6.3 \mathrm{y}$, mean $\mathrm{FEV}_{1} 2.4 \pm 0.6 \mathrm{~L}$ ). The subjects did not differ significantly at baseline. Pulmonary function measurements (reported for 40/50 subjects) included vital capacity and functional residual capacity. Pulmonary function measurements typically varied across the time points in each group but did not differ significantly among groups at follow-up on postoperative day 5. Mean oxygen saturation and stay were also not significantly different among the groups. Nearly $70 \%$ of all the subjects had some radiographic evidence of lung collapse or consolidation on the third postoperative day. Fourteen percent of the subjects across groups (4 in the CPT-only group, 5 in the 15-min-CPAP group, and 1 in the 30-min-CPAP group) had pulmonary complications (defined as fever $>24 \mathrm{~h}$, chest radiograph score of $\geq 2$, elevated white cell count, altered sputum, isolation of pathogen in sputum, or need for additional antibiotics). We rated the quality of the outcomes of oxygenation, pulmonary complications, and stay as fair. We rated the quality of the outcome of pulmonary function as poor.

Haeffener et al conducted an RCT assessing the effects of incentive spirometry plus expiratory positive airway pressure, compared with control techniques (coughing instructions, deep breathing exercises, early mobilization) on pulmonary function and complications in post-coronary-artery-bypass-graft subjects. ${ }^{17}$ The intervention group performed the incentive-spirometry protocol twice a day for 15-20 min; therapists gradually increased expiratory pressure to a maximum of $15 \mathrm{~cm} \mathrm{H}_{2} \mathrm{O}$. The incentivespirometry subjects continued the protocol at home postdischarge, with weekly telephone check-ins by study staff. Lung alterations on chest $\mathrm{x}$-ray (at 1 week post-surgery) were significantly lower among the incentive-spirometry subjects $(P<.001)$. At the 1 -month follow-up, pulmonary function improved from baseline in the incentive-spirometry group, whereas in the control group pulmonary function remained 10-26\% lower than baseline. Six-min-walk distance was higher in the incentive-spirometry group (data in figure only, $P<.001$ ). We rated the quality of the outcomes of pulmonary function, exercise tolerance, and stay as poor.

\section{Discussion}

The 32 studies that met our review criteria typically reported a small magnitude of treatment effect across a spectrum of interventions. The patient populations varied across the studies, and included subjects with COPD, bronchiectasis, and asthma, as well as ICU and trauma patients. The comparators used across studies also varied. While the studies often measured the same outcomes (eg, stay, oxygen saturation), they varied in reporting of outcomes and how the outcomes were measured (eg, sputum weight vs sputum volume). This heterogeneity meant that meta-analysis was not appropriate or feasible.

Variations of CPT were the most frequently studied intervention, but there is no standardized method for delivering CPT (Table 6), and inter-therapist variation and study technique variation may be important co-factors. Moreover, the subjects were often receiving critical care for more than one diagnosis, and the airway clearance outcomes and care modalities were likely not the primary determinant of the subject's condition or course of illness or recovery. Therefore, it is difficult to ascribe important clinical outcomes to the airway clearance intervention under study; and often surrogate or intermediate measures were utilized for comparison data.

We considered most studies of poor quality for the outcomes assessed (Table 7, and see the supplementary materials at http://www.rcjournal.com). Frequently used outcome measures for airway clearance techniques are limited in their accuracy and reliability, and most are difficult to tie to the effects of airway clearance specifically. ${ }^{12,46,47}$ Some measures, such as sputum weight or volume, have limited repeatability and specificity. Similarly, pulmonary function test results depend on the subject's effort and motivation, may be variably interpreted, and may not accurately reflect the effectiveness of a given clearance modality. ${ }^{46-48}$ We summarize study results by key outcomes below.

\section{Sputum Weight or Volume}

The studies measured sputum using both weight and volume. The measurement techniques differed: some studies assessed dry weight, others wet weight, and some used dedicated collection pots or other techniques. Two studies of poor quality for the outcome of sputum expectorated compared CPT and standard care and found no differences between the groups. ${ }^{16,22}$ For adults with bronchiectasis, a comparison of CPT versus ACBT, rated as poor quality, reported no significant difference in sputum volume or weight. ${ }^{25}$ Similarly, for adults with bronchiectasis, a comparison of CPT versus IPV, rated as fair quality, reported no significant difference in sputum volume or weight. ${ }^{26}$ Three different studies (all poor quality) of subjects with 3 different conditions assessed the effects of PEP versus CPT on sputum weight or in volume. Two studies reported no significant difference between PEP and the compari- 


\section{Nonpharmacologic Airway Clearance Techniques in Hospitalized Patients}

Table 6. Components of CPT in Studies Using CPT as a Treatment or Comparator

\begin{tabular}{|c|c|c|}
\hline First Author & Year & CPT Components* \\
\hline Paneroni ${ }^{26}$ & 2011 & FET, postural drainage, percussion, vibration, coughing \\
\hline Cross $^{15}$ & 2010 & Chest percussion, vibration, assisted coughing, positioning \\
\hline Chen $^{22}$ & 2009 & Positioning, mechanical vibration \\
\hline DiDario $^{19}$ & 2009 & Mechanical percussion \\
\hline Kodric $^{16}$ & 2009 & Expiration with glottis open in lateral posture \\
\hline Syed $^{25}$ & 2009 & Postural drainage, manual percussion, vibration, coughing, diaphragmatic breathing \\
\hline Paludo $^{20}$ & 2008 & Postural drainage, thoracic squeezing, percussion, vibration, cough stimulation \\
\hline Templeton ${ }^{21}$ & 2007 & Thoracic and pulmonary expansion, respiratory muscle exercise, manual hyperinflation, positioning, vibration \\
\hline Antonaglia $^{27}$ & 2006 & Percussion, postural drainage, expiration with glottis open in lateral posture \\
\hline Clini $^{18}$ & 2006 & Postural drainage, manual drainage \\
\hline Mackay ${ }^{39}$ & 2005 & Deep breathing, coughing, huffing, FET \\
\hline Tsang $^{29}$ & 2003 & Postural drainage, deep breathing, coughing \\
\hline Barker $^{37}$ & 2002 & Positioning, manual hyperinflation \\
\hline Berney $^{34}$ & 2002 & Postural drainage, manual hyperinflation, ventilator hyperinflation \\
\hline Ntoumenopoulos ${ }^{23}$ & 2002 & Postural drainage, positioning, vibration, coughing \\
\hline Denehy ${ }^{40}$ & 2001 & Deep breathing exercises, sustained maximal inspiration, FET, coughing \\
\hline de Charmoy ${ }^{41}$ & 2000 & Positioning, breathing exercises, coughing \\
\hline Krause $^{36}$ & 2000 & Postural drainage, percussion \\
\hline Ntoumenopoulos ${ }^{35}$ & 1998 & Postural drainage, manual hyperinflation \\
\hline Fagevik Olsén ${ }^{42}$ & 1997 & Breathing exercises, coughing, huffing \\
\hline Johnson $^{43}$ & 1996 & Deep breathing exercises, sustained maximal inspiration, postural drainage, manual percussion \\
\hline Ambrosino ${ }^{32}$ & 1995 & Postural drainage, manual chest percussion \\
\hline Johnson ${ }^{44}$ & 1995 & Deep breathing exercises, sustained maximal inspiration, postural drainage, manual percussion \\
\hline Asher $^{24}$ & 1990 & $\begin{array}{l}\text { Positioning, lateral costal breathing, diaphragmatic breathing, shoulder relaxation, postural drainage, coughing, } \\
\text { FET, vibration, wing flapping, percussion, thoracic mobility exercises, postural correction exercises }\end{array}$ \\
\hline \multicolumn{3}{|c|}{$\begin{array}{l}* \text { Patients typically also received suctioning, early mobilization, medical therapy, and standard turning per ICU protocols. } \\
\text { CPT = chest physiotherapy } \\
\text { FET = forced expiratory technique }\end{array}$} \\
\hline
\end{tabular}

son. ${ }^{33,45}$ One small study of adult ICU subjects with COPD reported more sputum in the intervention group. ${ }^{31}$

Three studies compared the Flutter device to a control intervention: 2 poor quality studies reported no significant difference. ${ }^{29,32}$ The third small study of ventilated adult ICU subjects reported more sputum in the intervention group. ${ }^{31}$ One poor quality study of postural drainage reported no significant difference in sputum measurements, ${ }^{33}$ whereas one good quality study of chest wall compression with a vest in patients with asthma and COPD reported no significant difference in sputum between the intervention group and the sham vest group. ${ }^{14}$

\section{Oxygenation and Gas Exchange}

Seven studies of CPT in various populations, including children with asthma, ${ }^{19,20,30}$ adults with COPD ${ }^{16}$ or bronchiectasis, ${ }^{26}$ and mechanically ventilated or postoperative subjects ${ }^{40,42}$ reported no significant between-group differences in oxygenation. Those studies were of good, ${ }^{26}$ fair, ${ }^{16,19,20,42}$ and poor $^{30,40}$ quality for this outcome. One good study of Flutter in mechanically ventilated subjects, and one fair study of IPV in subjects with COPD reported improved oxygenation in the intervention arms. ${ }^{28,38}$

Measurement of arterial blood gases, an indirect and invasive measure of the effectiveness of airway clearance interventions, was evaluated in 9 studies, all of which reported no significant difference in values between the groups: 2 were fair quality, and 4 were poor quality. ${ }^{18,32,33,36-38,41}$ A fair quality study of the Flutter device reported better values for adult ventilated subjects in the intervention group. ${ }^{28}$ Finally, a fair quality study reported worse values for subjects with COPD treated with CPT, compared with those treated with IPV. ${ }^{27}$

\section{Pulmonary Function Tests}

Thirteen studies, most of poor quality for pulmonary test outcomes, reported no significant difference in values between the groups. ${ }^{14,17,19,24,25,29,32,34,37,40,42,43,44}$ Three studies reported improved results: a poor quality study of IPV + CPT versus CPT in ICU subjects, with COPD reported better pulmonary function tests in the intervention group ${ }^{18}$; and a poor quality study of spirometry plus 
Table 7. Numbers of Studies Reporting Key Outcomes, by Quality Rating

\begin{tabular}{lccc}
\hline \hline \multirow{2}{*}{ Outcome } & \multicolumn{3}{c}{ Number of Studies } \\
\cline { 2 - 4 } & $\begin{array}{c}\text { Good } \\
\text { Studies }\end{array}$ & $\begin{array}{c}\text { Fair } \\
\text { Studies }\end{array}$ & $\begin{array}{c}\text { Poor } \\
\text { Studies }\end{array}$ \\
\hline Stay & 2 & 9 & 5 \\
Pulmonary function & 1 & 3 & 11 \\
Sputum weight/volume & 1 & 2 & 8 \\
Oxygenation & 2 & 4 & 4 \\
Gas exchange & 0 & 5 & 3 \\
Pulmonary complications & 1 & 2 & 4 \\
Duration of ventilation & 1 & 4 & 0 \\
Heart rate & 0 & 1 & 4 \\
Dyspnea & 1 & 0 & 3 \\
Harms of airway clearance techniques & 0 & 1 & 2 \\
Mean arterial pressure & 1 & 1 & 1 \\
Breathing frequency & 0 & 1 & 3 \\
Exercise tolerance & 0 & 0 & 2 \\
Quality of life & 0 & 0 & 2 \\
Need for ventilation & 1 & 3 & 0 \\
Hospital readmission (time to & 1 & 1 & 1 \\
$\quad$ exacerbation) & & & \\
Total & 12 & 37 & 53 \\
\hline
\end{tabular}

PEP compared with standard care in postoperative CABG subjects reported better pulmonary function in the intervention group..$^{17} \mathrm{~A}$ fair quality study reported that subjects in the Flutter arm had better pulmonary function, compared with those receiving standard care. ${ }^{28}$

\section{Need for and Progression to or Duration of Mechanical Ventilation}

For CPT compared to standard care in ventilated adult ICU subjects, 2 studies of fair quality reported ventilation days. One reported no significant difference in the duration, ${ }^{23}$ and the other reported a longer duration on the ventilator for the CPT (intervention) group. ${ }^{21} \mathrm{~A}$ fair quality study in COPD subjects receiving CPT or IPV reported no group difference in progression to ventilation, but a shorter duration of ventilation in the IPV group. ${ }^{27}$ Another fair quality study of IPV in COPD subjects reported that fewer IPV subjects progressed to ventilation, ${ }^{38}$ while in a study of CPT in postoperative subjects, progression to ventilation did not differ between the groups. ${ }^{39}$ In 2 fair quality studies of NIV ${ }^{31}$ versus routine ventilation, ${ }^{35}$ subjects receiving $\mathrm{PEP}^{31}$ required fewer ventilator days, but the duration did not differ in the study of postural drainage. ${ }^{35}$

\section{Signs and Symptoms}

Four studies rated poor quality for the outcome of heart rate included subjects with COPD, ${ }^{27}$ bronchiectasis, ${ }^{26}$ and postoperative ${ }^{43}$ or mechanically ventilated ICU subjects. ${ }^{37}$ Differences in heart rate were not significant between the groups in any of these studies. Similarly, 3 studies that assessed mean arterial pressure (one good quality study of Flutter vs usual care in mechanically ventilated ICU subjects, one fair quality study of IPV vs CPT in COPD subjects, and one poor quality study comparing CPT regimens in mechanically ventilated subjects) reported no significant group differences.

In studies that assessed breathing frequency, one fair quality study reported no differences in time to normal breathing frequency in children with pneumonia receiving either CPT or CPT plus usual care. ${ }^{20}$ One study of IPV in subjects with COPD reported no significant differences. ${ }^{27}$ Subjects with COPD or bronchiectasis receiving IPV improved significantly, compared with those who received usual care in 2 poor quality studies. ${ }^{26,38}$

Two studies, one poor quality study that compared CPT to usual care in COPD patients, ${ }^{16}$ and one good quality study that compared high-frequency chest wall compression to placebo, ${ }^{14}$ reported significant improvements in dyspnea in the intervention arms. Two poor quality studies that compared either IPV to $\mathrm{CPT}^{26}$ or CPT to $\mathrm{ACBT}^{15}$ reported no significant group differences.

\section{Exercise Tolerance}

Two studies were considered poor quality for the outcome of exercise tolerance. ${ }^{15,17}$ One compared CPT plus ACBT to ACBT alone, and reported significantly better tolerance among CPT subjects. ${ }^{15}$ Similarly, a small study of PEP versus usual care in postoperative subjects found improved walk distance in the PEP group. ${ }^{17}$

\section{Pulmonary Complications}

For adult ventilated ICU subjects, one good quality study of CPT found reduced risk of VAP, compared to the control intervention, ${ }^{23}$ and a fair quality study of IPV and standard care found reduced risk of VAP, compared to standard care alone. ${ }^{27}$ In a poor quality study of chest vibration in mechanically ventilated ICU subjects, vibration resulted in less atelectasis, compared to positioning. ${ }^{22}$ While studies have reported improved outcomes with intervention, the literature base is currently small, and the results are imprecise. Future studies may confirm or change current estimates.

For surgical patients, preoperative training reduced the risk of hospital-acquired pneumonia, compared to no preoperative training, in a poor quality study. ${ }^{42}$ Four other studies of airway clearance interventions in postoperative subjects reported no significant difference in complication rates: one good, one fair, and 2 poor quality studies. ${ }^{39-41,43}$ 
Stay

Stay, another indirect measure of CPT effectiveness, was reported in nearly half of the studies. For CPT compared to standard care, 5 studies ( 3 of poor quality, and 2 of fair quality) reported no significant difference. ${ }^{16,20,21,23,24}$ A fair quality study reported longer stay in COPD subjects treated with CPT, compared to those treated with IPV. ${ }^{27}$ Two studies of the Flutter device reported no significant difference in stay, compared to other standard treatments. ${ }^{29,30}$ A fair quality study of postural drainage and manual inflation versus standard care reported no significant difference in stay. ${ }^{35}$

A good quality study of a chest wall compression vest in subjects with asthma or COPD reported no significant difference in stay, compared to a sham vest. ${ }^{14}$ Two studies of IPV versus standard care in ICU subjects reported shorter stay in the subjects who received IPV. ${ }^{18,38}$

Three studies of airway clearance modalities in postoperative subjects reported shorter stay in the treatment groups. ${ }^{39,40,44}$ The studies reporting stay were in different patient populations, and used different interventions and comparators, and stay is an indirect outcome measure, so the studies could not be combined meaningfully.

\section{Exacerbations/Hospital Readmissions}

Three studies (one good, ${ }^{14}$ one fair, ${ }^{15}$ one poor ${ }^{16}$ quality) that assessed different interventions (high-frequency chest wall compression or variations of CPT) in subjects with COPD reported no significant group differences in the number of admissions or exacerbations.

\section{Quality of Life}

Two poor quality studies of subjects with COPD, one that compared CPT to ACBT, ${ }^{15}$ and one that compared CPT with usual care, ${ }^{16}$ reported no significant group differences in quality of life as assessed on the SGRQ and other measures.

\section{Harms of Airway Clearance Techniques}

Three studies reported harms specific to the airway clearance modalities. ${ }^{15,26,34}$ One poor quality study noted a significantly lower incidence of harms in the IPV arm, whereas the others did not report the significance.

\section{Methodologic Considerations and Limitations}

The small magnitude of treatment effects, the uncertain and high risks of bias of the included studies, and the small number of studies that used clinically meaningful outcomes significantly limits the potential impact of the present re- view's findings for individuals, guideline panels, and healthcare policy-makers. More than half of the studies were rated as having high risk of bias, on the basis of allocation concealment, but this is in the face of the fact that concealment would be a major challenge in this type of research. Prior surgical sham studies, however, would suggest that it is possible. The complexity of care, and the fact that many other factors were more powerful drivers of important clinical outcomes, render it difficult to tease out the specific effect of the interventions on important clinical outcomes (Table 8). Indeed, the comparison is frequently poorly described or not described, and with "usual care" lacking standardization, it is challenging to assess the impact of airway clearance interventions. As shown in the tables throughout this report, neither the interventions nor the comparators were consistent across any subset of studies. There were few controls for variation in technique, for example among therapists, and the interventions were typically poorly characterized in terms of duration and quantity. In addition, the studies routinely failed to identify or capture harms of the intervention.

Nonetheless, although the differences in effect were typically not significant, it is possible that the effects are meaningful in patients' experience and perception. It is unclear whether small changes in pulmonary function measured by sputum weight, sputum volume, and blood gases translate to subjective changes in patient comfort. Few of the studies included any assessment of comfort or quality of life, and we suggest that comfort and quality of life are important areas for further exploration. Important outcomes to consider include exacerbations and health-related quality of life.

\section{Future Research}

In building the body of evidence, initial studies should establish the effectiveness of individual interventions against placebo, and then proceed to head to head comparisons among interventions. Without the placebo-versus-intervention studies, head to head comparisons yielding nonsignificant results cannot establish the effectiveness of either intervention. Researchers in this field should be encouraged to use standard RCT methodology, with random sequence generation, and to develop approaches for good allocation concealment. In this way, even small studies would be more useful for providing a basis for guidance. However, ultimately, because of the complexity of the patient condition and the numerous modalities of care, large studies with the ability to match patient and care characteristics are essential.

The promising studies in the review should be repeated with rigorous methods, and with similar populations, interventions, comparators, and outcomes, thus enabling future meta-analysis to generate adequately powered esti- 
Nonpharmacologic Airway Clearance Techniques in Hospitalized Patients

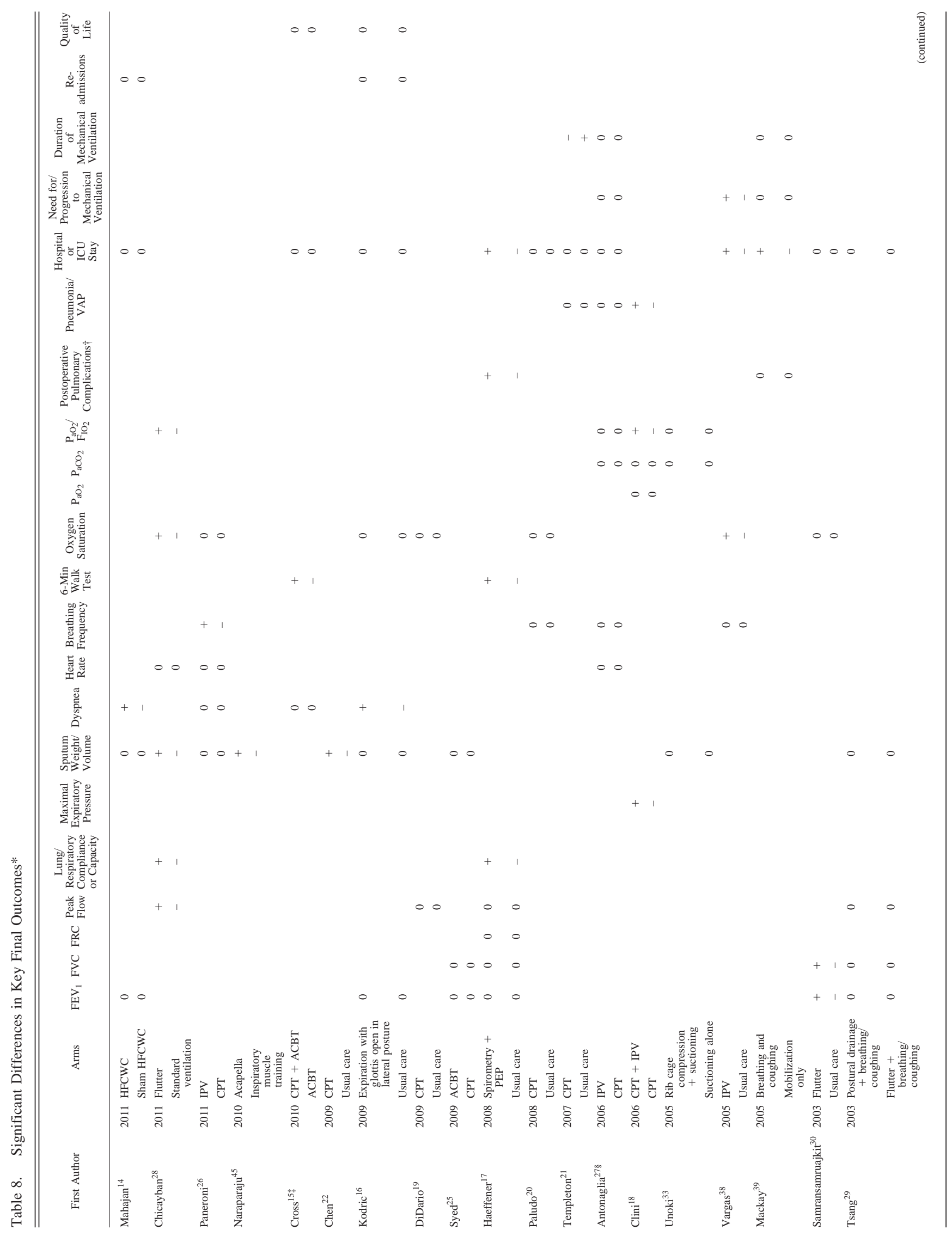


Nonpharmacologic Airway Clearance Techniques in Hospitalized Patients

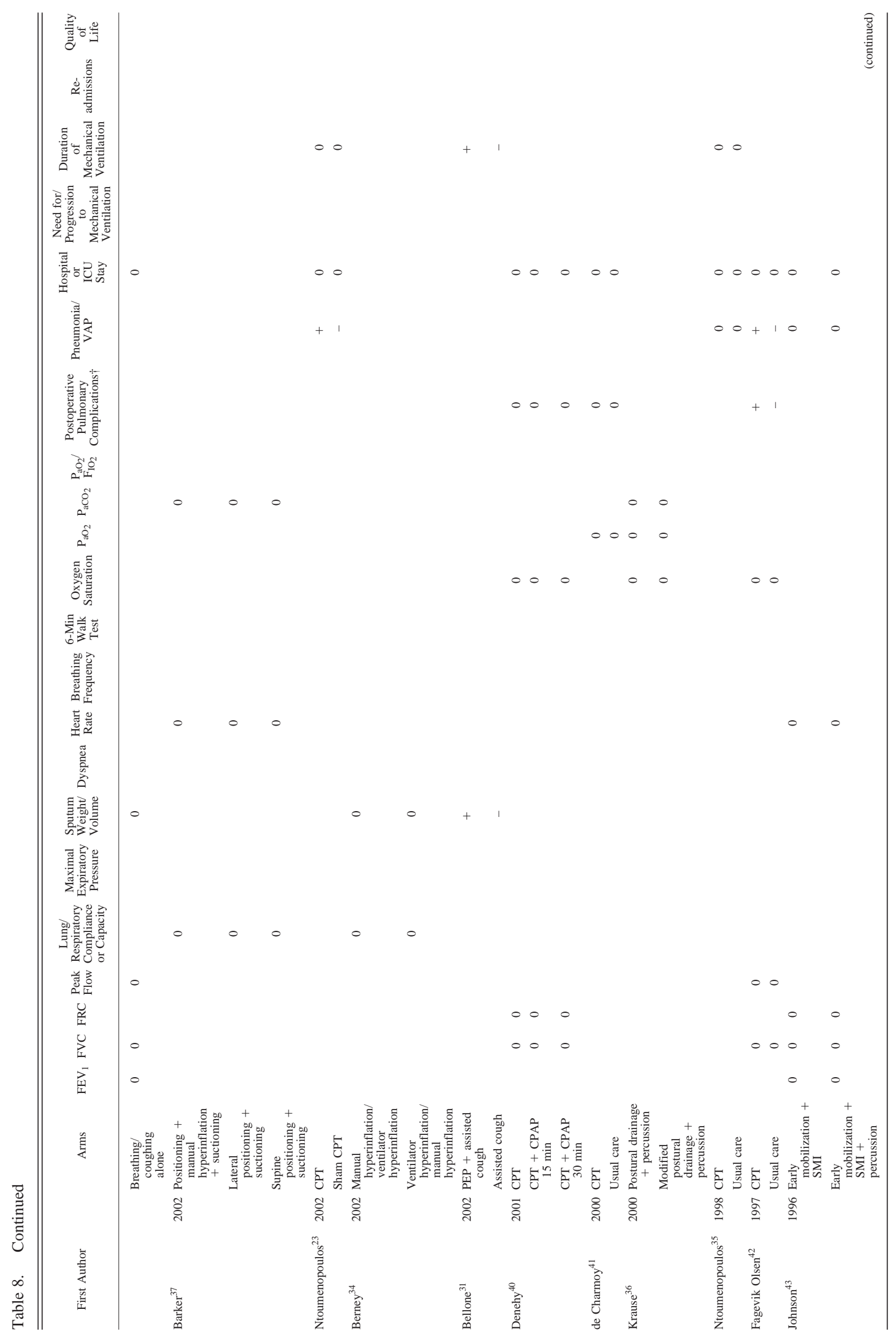




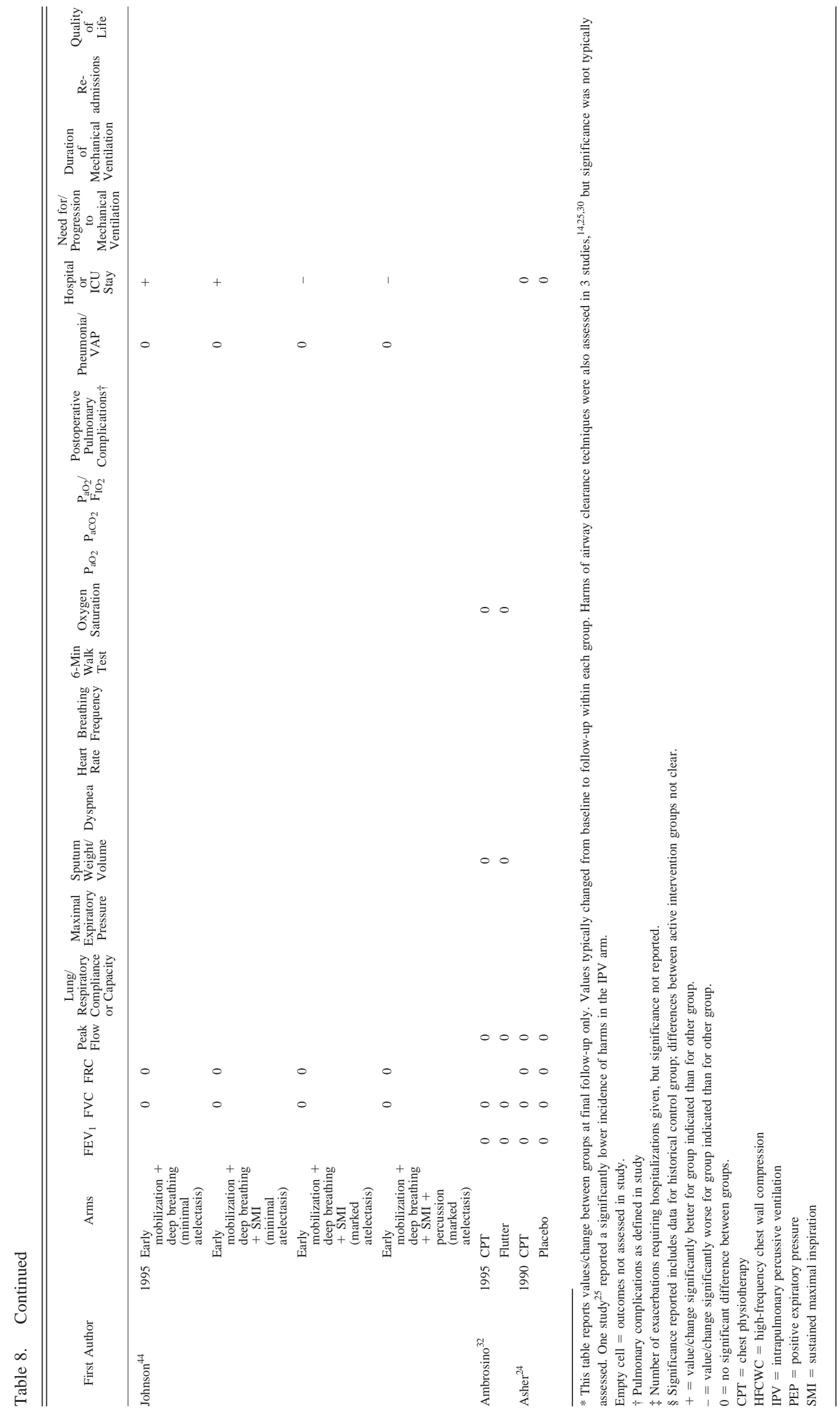




\section{Nonpharmacologic Airway Clearance Techniques in Hospitalized Patients}

mates of effect. The elements of the intervention should be standardized, and the characteristics of the comparator well described. As a field, respiratory care should consider assessing the degree to which study outcomes are clinically meaningful, and agreeing on a set of core outcomes for future work.

\section{Summary}

In summary, the 32 studies included in this review provide limited evidence for the effectiveness of nonpharmacologic airway clearance techniques. The evidence we reviewed indicates that airway clearance techniques are probably safe for ventilated ICU patients, and confer zero to small benefit to some clinical outcomes. ${ }^{18,21-23,28,33-37}$ Consideration may be given to the use of airway clearance techniques for ventilated ICU patients, to reduce the risk of acquiring pneumonia, based upon 2 studies, which included 76 subjects. ${ }^{23,27}$ Based on the current limited evidence, airway clearance modalities might not be recommended as routine prophylaxis to prevent postoperative pulmonary complications in adults. ${ }^{39-43}$ Similarly, in people with COPD, data from 6 single studies that specifically targeted COPD did not provide evidence of significant short-term benefit from airway clearance modalities. ${ }^{14-16,27,31,38}$

Our finding of limited evidence is in line with similar, recent reviews of airway clearance in patients with COPD and pneumonia, which have generally found small benefits. ${ }^{11,12,49,50}$ The interventions, comparators, and populations varied considerably across the studies, hampering our ability to draw firm conclusions. The interventions, including conventional CPT, IPV, and PEP, typically provided small benefits to pulmonary function, gas exchange, oxygenation, and the need for or duration of ventilation, among other outcomes, but the between-group differences were generally small and not significant. The harms of airway clearance techniques were not consistently reported, though airway clearance techniques were generally considered safe in studies that did comment on adverse effects. Further research with clearly characterized populations and interventions is needed to understand the potential benefits and harms of these techniques.

\section{ACKNOWLEDGMENTS}

We gratefully acknowledge the contributions of the American Association for Respiratory Care (AARC) Airway Clearance Clinical Practice Guidelines Committee, whose insights on scoping the literature and reviewing the studies were invaluable. The committee includes Richard Branson MSc RRT FAARC, Gail Drescher MA RRT, Carl Haas MLS RRT FAARC, Dean Hess PhD RRT FAARC, Ray Masferrer RRT FAARC, Catherine O'Malley RRT-NPS, Bruce Rubin MD MEngr MBA FAARC, Shawna Strickland PhD RRT-NPS AE-C FAARC, Teresa Volsko MHHS RRT FAARC.

\section{REFERENCES}

1. Laurent GJ, Shapiro SD. Encyclopedia of respiratory medicine. Amsterdam: Elsevier 2006:332-343.

2. Reid WD, Brown JA, Konnyu KJ, Rurak JM, Sakakibara BM. Physiotherapy secretion removal techniques in people with spinal cord injury: a systematic review. J Spinal Cord Med 2010;33(4):353-370.

3. McCool FD, Rosen MJ. Nonpharmacologic airway clearance therapies: ACCP evidence-based clinical practice guidelines. Chest 2006; 129(1 Suppl):250S-259S.

4. Main E. What is the best airway clearance technique in cystic fibrosis? Paediatr Respir Rev 2013;14(Suppl 1):10-12.

5. Pisi G, Chetta A. Airway clearance therapy in cystic fibrosis patients. Acta Biomed 2009;80(2):102-106.

6. Bradley JM, Moran FM, Elborn JS. Evidence for physical therapies (airway clearance and physical training) in cystic fibrosis: an overview of five Cochrane systematic reviews. Respir Med 2006;100(2): 191-201.

7. Jones AP, Rowe BH. Bronchopulmonary hygiene physical therapy for chronic obstructive pulmonary disease and bronchiectasis. Cochrane Database Syst Rev 2000;(2):CD000045.

8. Schechter MS. Airway clearance applications in infants and children. Respir Care 2007;52(10):1382-1390, discussion 1390-1391.

9. Bruurs ML, van der Giessen LJ, Moed H. The effectiveness of physiotherapy in patients with asthma: a systematic review of the literature. Respir Med 2013;107(4):483-494.

10. Jones A, Rowe BH. Bronchopulmonary hygiene physical therapy in bronchiectasis and chronic obstructive pulmonary disease: a systematic review. Heart Lung 2000;29(2):125-135.

11. Hill K, Patman S, Brooks D. Effect of airway clearance techniques in patients experiencing an acute exacerbation of chronic obstructive pulmonary disease: a systematic review. Chron Respir Dis 2010; 7(1):9-17.

12. Osadnik CR, McDonald CF, Jones AP, Holland AE. Airway clearance techniques for chronic obstructive pulmonary disease. Cochrane Database Syst Rev 2012;3:3.

13. Flume PA, Robinson KA, O'Sullivan BP, Finder JD, Vender RL, Willey-Courand DB, et al. Cystic fibrosis pulmonary guidelines: airway clearance therapies. Respir Care 2009;54(4):522-537.

14. Mahajan AK, Diette GB, Hatipoglu U, Bilderback A, Ridge A, Harris VW, et al. High frequency chest wall oscillation for asthma and chronic obstructive pulmonary disease exacerbations: a randomized sham-controlled clinical trial. Respir Res 2011;12:120.

15. Cross J, Elender F, Barton G, Clark A, Shepstone L, Blyth A, et al A randomised controlled equivalence trial to determine the effectiveness and cost-utility of manual chest physiotherapy techniques in the management of exacerbations of chronic obstructive pulmonary disease (MATREX). Health Technol Assess 2010;14(23):1-147, iiiiv.

16. Kodric M, Garuti G, Colomban M, Russi B, Porta RD, Lusuardi M, et al. The effectiveness of a bronchial drainage technique (ELTGOL) in COPD exacerbations. Respirology 2009;14(3):424-428.

17. Haeffener MP, Ferreira GM, Barreto SS, Arena R, Dall'Ago P. Incentive spirometry with expiratory positive airway pressure reduces pulmonary complications, improves pulmonary function and 6-minute walk distance in patients undergoing coronary artery bypass graft surgery. Am Heart J 2008;156(5):900, e901-e908.

18. Clini EM, Antoni FD, Vitacca M, Crisafulli E, Paneroni M, ChezziSilva $\mathrm{S}$, et al. Intrapulmonary percussive ventilation in tracheostomized patients: a randomized controlled trial. Intensive Care Med 2006;32(12):1994-2001.

19. DiDario AG, Whelan MA, Hwan WH, Yousef E, Cox TJ, Oldham $\mathrm{HM}$, et al. Efficacy of chest physiotherapy in pediatric patients with acute asthma exacerbations. Pediatr Asthma Allergy Immunol 2009; 22(2):69-74. 


\section{Nonpharmacologic Airway Clearance Techniques in Hospitalized Patients}

20. Paludo C, Zhang L, Lincho CS, Lemos DV, Real GG, Bergamin JA. Chest physical therapy for children hospitalised with acute pneumonia: a randomised controlled trial. Thorax 2008;63(9):791-794.

21. Templeton M, Palazzo MG. Chest physiotherapy prolongs duration of ventilation in the critically ill ventilated for more than 48 hours. Intensive Care Med 2007;33(11):1938-1945.

22. Chen YC, Wu LF, Mu PF, Lin LH, Chou SS, Shie HG. Using chest vibration nursing intervention to improve expectoration of airway secretions and prevent lung collapse in ventilated ICU patients: a randomized controlled trial. J Chin Med Assoc 2009;72(6):316-322.

23. Ntoumenopoulos G, Presneill JJ, McElholum M, Cade JF. Chest physiotherapy for the prevention of ventilator-associated pneumonia. Intensive Care Med 2002;28(7):850-856.

24. Asher MI, Douglas C, Airy M, Andrews D, Trenholme A. Effects of chest physical therapy on lung function in children recovering from acute severe asthma. Pediatr Pulmonol 1990;9(3):146-151.

25. Syed N, Maiya AG, Siva Kumar T. Active Cycles of Breathing Technique (ACBT) versus conventional chest physical therapy on airway clearance in bronchiectasis: a crossover trial. Adv Physiother 2009;11(4):193-198.

26. Paneroni M, Clini E, Simonelli C, Bianchi L, Degli Antoni F, Vitacca M. Safety and efficacy of short-term intrapulmonary percussive ventilation in patients with bronchiectasis. Respir Care 2011; 56(7):984-988

27. Antonaglia V, Lucangelo U, Zin WA, Peratoner A, De Simoni L, Capitanio $\mathrm{G}$, et al. Intrapulmonary percussive ventilation improves the outcome of patients with acute exacerbation of chronic obstructive pulmonary disease using a helmet. Crit Care Med 2006;34(12): 2940-2945.

28. Chicayban LM, Zin WA, Guimaraes FS. Can the Flutter valve improve respiratory mechanics and sputum production in mechanically ventilated patients? A randomized crossover trial. Heart Lung 2011; 40(6):545-553.

29. Tsang SM, Jones AY. Postural drainage or Flutter device in conjunction with breathing and coughing compared to breathing and coughing alone in improving secretion removal and lung function in patients with acute exacerbation of bronchiectasis: a pilot study. H K Physiother J 2003;21:29-36.

30. Samransamruajkit R, Chin TW, Yuengsrigul A, Newton T, Nussbaum E. Possible beneficial effect of chest physical therapy in hospitalized asthmatic children. Pediatr Asthma Allergy Immunol 2003; 16(4):295-303.

31. Bellone A, Spagnolatti L, Massobrio M, Bellei E, Vinciguerra R, Barbieri A, et al. Short-term effects of expiration under positive pressure in patients with acute exacerbation of chronic obstructive pulmonary disease and mild acidosis requiring non-invasive positive pressure ventilation. Intensive Care Med 2002;28(5):581-585.

32. Ambrosino N, Callegari G, Galloni C, Brega S, Pinna G. Clinical evaluation of oscillating positive expiratory pressure for enhancing expectoration in diseases other than cystic fibrosis. Monaldi Arch Chest Dis 1995;50(4):269-275.

33. Unoki T, Kawasaki Y, Mizutani T, Fujino Y, Yanagisawa Y, Ishimatsu $\mathrm{S}$, et al. Effects of expiratory rib-cage compression on oxygenation, ventilation, and airway-secretion removal in patients receiving mechanical ventilation. Respir Care 2005;50(11):1430-1437.
34. Berney S, Denehy L. A comparison of the effects of manual and ventilator hyperinflation on static lung compliance and sputum production in intubated and ventilated intensive care patients. Physiother Res Int 2002;7(2):100-108.

35. Ntoumenopoulos G, Gild A, Cooper DJ. The effect of manual lung hyperinflation and postural drainage on pulmonary complications in mechanically ventilated trauma patients. Anaesth Intensive Care 1998; 26(5):492-496

36. Krause MW, Van Aswegen H, De Wet EH, Joubert G. Postural drainage in intubated patients with acute lobar atelectasis: a pilot study. S African J Physiother 2000;56(3):29-32.

37. Barker M, Adams S. An evaluation of a single chest physiotherapy treatment on mechanically ventilated patients with acute lung injury. Physiother Res Int 2002;7(3):157-169.

38. Vargas F, Bui HN, Boyer A, Salmi LR, Gbikpi-Benissan G, Guenard $\mathrm{H}$, et al. Intrapulmonary percussive ventilation in acute exacerbations of COPD patients with mild respiratory acidosis: a randomized controlled trial. Crit Care 2005;9(4):R382-R389.

39. Mackay MR, Ellis E, Johnston C. Randomised clinical trial of physiotherapy after open abdominal surgery in high risk patients. Aust $\mathrm{J}$ Physiother 2005;51(3):151-159.

40. Denehy L, Carroll S, Ntoumenopoulos G, Jenkins S. A randomized controlled trial comparing periodic mask CPAP with physiotherapy after abdominal surgery. Physiother Res Int 2001;6(4):236-250.

41. de Charmoy SB, Eales CJ. The role of prophylactic chest physiotherapy after cardiac valvular surgery: is there one? S African J Physiother 2000;56(3):24-28.

42. Fagevik Olsén M, Hahn I, Nordgren S, Lonroth H, Lundholm K. Randomized controlled trial of prophylactic chest physiotherapy in major abdominal surgery. Br J Surg 1997;84(11):1535-1538.

43. Johnson D, Kelm C, Thomson D, Burbridge B, Mayers I. The effect of physical therapy on respiratory complications following cardiac valve surgery. Chest 1996;109(3):638-644.

44. Johnson D, Kelm C, To T, Hurst T, Naik C, Gulka I, et al. Postoperative physical therapy after coronary artery bypass surgery. Am J Respir Crit Care Med 1995;152(3):953-958.

45. Naraparaju S, Vaishali K, Venkatesan P, Acharya V. A comparison of the Acapella and a threshold inspiratory muscle trainer for sputum clearance in bronchiectasis: a pilot study. Physiother Theory Pract 2010;26(6):353-357.

46. Pellegrino R, Viegi G, Brusasco V, Crapo RO, Burgos F, Casaburi $\mathrm{R}$, et al. Interpretative strategies for lung function tests. Eur Respir J 2005;26(5):948-968

47. Marques A, Bruton A, Barney A. Clinically useful outcome measures for physiotherapy airway clearance techniques: a review. Phys Ther Rev 2006;11(4):299-307.

48. Hyatt RE, Scanlon PD, Nakamura M. Interpretation of pulmonary function tests: a practical guide. Philadelphia: Lippincott Williams \& Wilkins; 2009.

49. Yang M, Yan Y, Yin X, Wang BY, Wu T, Liu GJ, et al. Chest physiotherapy for pneumonia in adults. Cochrane Database Syst Rev 2010;(2):2.

50. Ides K, Vissers D, De Backer L, Leemans G, De Backer W. Airway clearance in COPD: need for a breath of fresh air? A systematic review. COPD 2011;8(3):196-205. 